\title{
Molecular Underpinnings of Motor Pattern Generation: Differential Targeting of Shal and Shaker in the Pyloric Motor System
}

\author{
Deborah J. Baro, ${ }^{1,2}$ Amir Ayali, ${ }^{2}$ Lauren French, ${ }^{2}$ Nathaniel L. Scholz, ${ }^{3}$ Jana Labenia, ${ }^{3}$ Cathy C. Lanning, ${ }^{2}$ \\ Katherine Graubard, ${ }^{3}$ and Ronald M. Harris-Warrick ${ }^{2}$ \\ 1/nstitute of Neurobiology and Department of Biochemistry, Medical Sciences Campus, University of Puerto Rico, San \\ Juan, Puerto Rico 00901, 2Department of Neurobiology and Behavior, Cornell University, Ithaca, New York 14850, and \\ ${ }^{3}$ Department of Zoology, University of Washington, Seattle, Washington 98195
}

The patterned activity generated by the pyloric circuit in the stomatogastric ganglion of the spiny lobster, Panulirus interruptus, results not only from the synaptic connectivity between the 14 component neurons but also from differences in the intrinsic properties of the neurons. Presumably, differences in the complement and distribution of expressed ion channels endow these neurons with many of their distinct attributes. Each pyloric cell type possesses a unique, modulatable transient potassium current, or A-current $\left(I_{A}\right)$, that is instrumental in determining the output of the network. Two genes encode A-channels in this system, shaker and shal. We examined the hypothesis that cellspecific differences in shaker and shal channel distribution contribute to diversity among pyloric neurons. We found a stereotypic distribution of channels in the cells, such that each channel type could contribute to different aspects of the firing properties of a cell. Shal is predominantly found in the somatodendritic compartment in which it influences oscillatory behavior and spike frequency. Shaker channels are exclusively localized to the membranes of the distal axonal compartments and most likely affect distal spike propagation. Neither channel is detectably inserted into the preaxonal or proximal portions of the axonal membrane. Both channel types are targeted to synaptic contacts at the neuromuscular junction. We conclude that the differential targeting of shaker and shal to different compartments is conserved among all the pyloric neurons and that the channels most likely subserve different functions in the neuron.

Key words: potassium channel; A-current; gene expression; subcellular distribution; neural network; location versus function; stomatogastric; mRNA; immunocytochemistry; Kv4
A variety of rhythmic behaviors, such as locomotion, depend on the relatively automatic execution of a series of motor actions. Neuronal circuits that drive circumscribed sets of muscles to generate such behaviors are called central pattern generators (CPGs). A particularly powerful model circuit for investigating motor control is the pyloric CPG, located in the stomatogastric ganglion (STG) of arthropods (Harris-Warrick et al., 1992; Marder and Calabrese, 1996; Marder, 1998). The motor task, the output of the network (motor pattern), the neuronal components of the network, their synaptic interactions, and their modulation have been extensively characterized and modeled over the last 25 years. More recently, the genes encoding the voltage-dependent $\mathrm{K}^{+}$channels in this system have been cloned, and protocols for studying these molecular entities in individual identified pyloric neurons have been established (for review, see Baro and Harris-Warrick, 1998). Thus, the pyloric network provides an excellent context in which to study how $\mathrm{K}^{+}$channel expression patterns contribute to the generation of motor behavior.

It has been demonstrated that variations in the amplitude and biophysical properties of the transient potassium current $\left(I_{\mathrm{A}}\right)$ in different pyloric neurons play key roles in determining the order

Received April 4, 2000; revised June 15, 2000; accepted June 16, 2000.

This work was supported by National Institutes of Health Grants RO1 NS38770 (D.J.B.), RO1 NS15697 (K.G.), and RO1 NS35631 (R.H.W.), and Research Center in Minority Institution Award G12RR-03051. We thank Drs. D. Hartline, P. Meyrand, J. Simmers, and A. Selverston for cogent discussions on channel localization, and Dr. J. Trimmer for technical advice on the production and use of antibodies. We gratefully acknowledge the kind gift of an electron micrograph from Dr. D. King. Additionally, we thank Drs. M. Sosa, M. Miller, J. Peck, and the anonymous reviewers for useful comments on this manuscript, and Carol Bayles for outstanding assistance with confocal microscopy.

Correspondence should be addressed to Deborah J. Baro, Institute of Neurobiology, 201 Boulevard del Valle, San Juan, PR 00901. E-mail: djbaro@neurobio.upr.clu.edu.

A.A.'s present address: Department Zoology, Faculty of Life Sciences, Tel Aviv University, Ramat Aviv, Tel-Aviv, 69978, Israel.

N.L.S.'s present address: Northwest Fisheries Science Center, 2725 Montlake Boulevard East, Seattle, WA 98112.

Copyright (C) 2000 Society for Neuroscience $0270-6474 / 00 / 206619-12 \$ 15.00 / 0$ of neuronal firing and phase relationships in the motor pattern (Hartline, 1979; Graubard and Hartline, 1991; Tierney and HarrisWarrick, 1992; Harris-Warrick et al., 1995a,b; Baro et al., 1997). There are two A-channel $\alpha$-subunit-encoding genes in arthropods, shaker and shal (Salkoff et al., 1992; Tsunoda and Salkoff 1995a,b; Baro et al., 1996a; Kim et al., 1997, 1998). Studies at the transcriptional level suggest that all pyloric neurons express both genes (Baro et al., 1996b, 1997). Thus, variations in $I_{\text {A }}$ could be generated by differential expression of Shaker and Shal in the different pyloric neurons. In particular, differential targeting of the channels in each neuronal cell type could lead to variations in firing properties that help to pattern motor output.

To better understand the principles underlying the functional correlates of $I_{\mathrm{A}}$ diversity, we sought to define the distribution of Shaker and Shal channels in pyloric neurons. We raised rabbit polyclonal antibodies against either lobster Shaker or Shal channels and used these antibodies in conjunction with standard immunocytochemistry (ICC) and confocal microscopy to localize the channels in the stomatogastric nervous system (STNS). Our results suggest that disparate firing properties do not arise from differential placement of Shaker versus Shal channels among pyloric neurons.

\section{MATERIALS AND METHODS}

Production of antibodies. We chose small regions of the lobster Shal and Shaker proteins to serve as the antigens for antibody production. The lobster Shal peptide was CLEKTTDREFVELEVPYNGQ. The lobster Shaker peptide was SLPKLSSQDDDGPPQTNFIGTGNFEPIPHDHDFC. The Shal peptide shows no homology to the shaker channel. Similarly, the Shaker peptide shows no homology to the Shal channel. Because each epitope is specific for its respective channel, the antibodies should not cross-react with the inappropriate channel. Using standard recombinant techniques, we cloned each of the DNA sequences representing these peptides into two expression vectors. One expression vector contained a glutathione $S$-transferase (GST) tag (Amersham Pharmacia Biotech, Piscataway, NJ), whereas the other contained a pinpoint tag (Promega, Madison, WI). The four corresponding fusion proteins (GST-Shaker, pinpoint-Shaker, GST-Shal, and pinpoint-Shal) were isolated using proto- 
cols supplied by the manufacturer of each expression vector. The GSTShaker and GST-Shal fusion proteins served as immunogens, and each was injected into a different rabbit. The two pinpoint fusion proteins were used to make affinity columns consisting of the pinpoint fusion protein linked to tetralink resin (Promega). Using a standard protocol (Harlow and Lanr, 1988), we passed the serum obtained from one of the immunized rabbits over the appropriate affinity column and isolated the anti-lobster-specific antibodies while excluding the majority of the anti-GST antibodies, as well as endogenous rabbit antibodies. Like antibody fractions were pooled, and Centricon plus 20 ultrafiltration devices (molecular weight cutoff of 50,000; Millipore, Bedford, MA) were used to concentrate and dialyze each antibody. Antibodies at a final concentration of $2 \mathrm{mg} / \mathrm{ml}$ (anti-Shal) and 1 $\mathrm{mg} / \mathrm{ml}$ (anti-Shaker) were aliquoted and stored at $-70^{\circ} \mathrm{C}$. Three additional anti-Shaker antibodies (AS2, AS3, and AS4) were raised against different intracellular and extracellular epitopes and affinity purified.

Protein extractions. Two methods were used to obtain protein extracts. Both methods worked equally well. Method 1 was as follows. Fresh tissue was removed to a sterile mortar containing liquid $\mathrm{N}_{2}$. Tissue was ground to a fine powder with a sterile pestle, taking care not to let the liquid $\mathrm{N}_{2}$ evaporate completely. Powdered tissue was removed to a sterile tube and stored at $-70^{\circ} \mathrm{C}$ indefinitely. Two grams of powdered tissue were added to a beaker containing $10 \mathrm{ml}$ of lysis buffer [0.5\% SDS, $1 \%$ Triton X-100, 1 mM iodoacetamide, $1 \mathrm{~mm}$ PMSF, $1 \mathrm{~mm}$ EDTA, and $1 \mu \mathrm{g} / \mathrm{ml}$ aprotinin, in $1 \times$ PBS $\left(0.14 \mathrm{M} \mathrm{NaCl}, 0.27 \mathrm{mM} \mathrm{KCl}, 10 \mathrm{~mm} \mathrm{Na} \mathrm{HPO}_{4}\right.$, and $0.18 \mathrm{~mm}$ $\mathrm{KH}_{2} \mathrm{PO}_{4}$, pH 7.3)] at $4^{\circ} \mathrm{C}$. While constantly stirring, a sterile spatula was used to add small amounts of the powdered tissue to the beaker, waiting to add the next aliquot until the previous one was no longer floating on the surface. The preparation was stirred $1 \mathrm{hr}$ at $4^{\circ} \mathrm{C}$ and spun at $12,000 \mathrm{rpm}$ for $20 \mathrm{~min}$. The supernatant was recovered, mixed with an equal volume of $3 \times$ loading buffer (175 mm Tris, $\mathrm{pH} 6.8,5 \%$ SDS, $24 \%$ glycerol, $0.3 \mathrm{~m}$ DTT, and $0.06 \%$ bromophenol blue), and boiled for $20 \mathrm{~min}$. The protein preparation could then be stored at $4^{\circ} \mathrm{C}$ indefinitely. Fifteen microliters were electrophoresed per lane on an SDS-polyacrylamide gel.

Method 2 was as follows. The tissue was isolated, minced, weighed, and immediately frozen on dry ice. The tissue was then placed in a tissue homogenizer at $4^{\circ} \mathrm{C}$, and $2 \mathrm{ml}$ of lysis buffer per $100 \mathrm{mg}$ tissue was added. The tissue was homogenized with a pestle using $\sim 100$ strokes. The homogenate was removed to an eppendorf tube and stirred at $4^{\circ} \mathrm{C}$ for $1 \mathrm{hr}$ and spun at $12,000 \mathrm{rpm}$ for $20 \mathrm{~min}$; the supernatant was stored at $-20^{\circ} \mathrm{C}$ indefinitely.

Western blots. Protein extracts from lobster muscles and nervous tissue were transferred from an SDS-polyacrylamide gel to a polyvinylidene difluoride membrane (MSI, Westboro, MA) using a semidry electroblotting apparatus $(\mathrm{OWL})$. The blot was shaken at room temperature $4 \mathrm{hr}$ to overnight in blocking buffer $(1 \times$ PBS containing $4 \%$ powdered milk and $0.3 \%$ Tween 20). The membrane was transferred to a solution containing the primary antibody diluted 1:1000 (anti-Shaker) or 1:5000 (anti-Shal) in blocking buffer and shaken at room temperature overnight. The membrane was washed in three changes of PBS plus $0.3 \%$ Tween 20 for 10 min each and then transferred to a solution containing a 1:10,000 dilution of the secondary antibody (goat-anti rabbit IgG conjugated to alkaline phosphatase; Sigma, St. Louis, MO) in blocking buffer. The membrane was shaken at room temperature $2 \mathrm{hr}$ to overnight, washed in three changes of TTBS (20 mM Tris, pH 7.5, $500 \mathrm{~mm} \mathrm{NaCl}$, and $0.2 \%$ Tween 20), 10 min each, and processed with a chemiluminescent substrate (Bio-Rad, Hercules, CA) according to the directions of the manufacturer. To demonstrate that the staining pattern represented lobster channel distribution, we always performed a series of controls in which we excluded the primary antibody and replaced the primary antibody with preimmune serum.

Immunocytochemistry and confocal microscopy. We used a slight modification of the method described by Scholz et al. (1998). Panulirus interruptus were purchased from Don and Laurice Tomlinson (San Diego, CA) and maintained at $16^{\circ} \mathrm{C}$. The brain and appropriate STNS tissue were dissected out and fixed in $3.2 \%$ paraformaldehyde in $1 \times$ PBS for $2 \mathrm{hr}$ at $4^{\circ} \mathrm{C}$. To facilitate antibody penetration, care was taken during the dissections to (1) remove the perineural sheath dorsal to the ganglia, (2) either cut long tracts of nerves into $0.5-2 \mathrm{~mm}$ segments or desheath significant portions of the nerves, and (3) separate muscles into smaller bundles containing three to eight fibers. The fix was washed out with eight changes of PBST (PBS plus $0.3 \%$ Triton X-100) over 2-8 hr with constant shaking at $4^{\circ} \mathrm{C}$. The STNS tissue then received $400 \mu \mathrm{l}$ of primary antibody solution: $1 \times$ PBST plus $5 \%$ normal goat serum (NGS) plus primary antibody $(0.5$ $\mu \mathrm{g} / \mathrm{ml}$ anti-Shaker or $0.2 \mu \mathrm{g} / \mathrm{ml}$ anti-Shal). The secondary antibody was preabsorbed with lobster brain to reduce nonspecific binding. The brain received $400 \mu \mathrm{l}$ of secondary antibody solution: $1 \times$ PBST plus 5\% NGS plus $1 \mu \mathrm{l}$ of undiluted secondary antibody [goat anti-rabbit Texas Red (Jackson ImmunoResearch, West Grove, PA) or goat anti-mouse Texas Red (Molecular Probes, Eugene, OR), or goat anti-mouse Oregon Green (Molecular Probes) or goat anti-rabbit Oregon Green (Molecular Probes)] Any preparation containing the secondary antibody solution was always protected from light by wrapping the preparation in aluminum foil. When the STNS tissue being studied included more than just the STG, the secondary antibody was preabsorbed with pieces of muscle and thoracic and abdominal ganglia, in addition to brain. Both preparations (primary and secondary) were incubated $36-48 \mathrm{hr}$ at $4^{\circ} \mathrm{C}$ with constant shaking. The primary antibody was washed out with eight changes of PBST over 2-8 hr with constant shaking at $4^{\circ} \mathrm{C}$. The brain was discarded, and the preab- sorbed secondary antibody solution was added to the STNS tissue and incubated overnight with constant shaking at $4^{\circ} \mathrm{C}$. The secondary antibody was washed out with eight changes of PBS with constant shaking at $4^{\circ} \mathrm{C}$ over $2-8 \mathrm{hr}$. The tissue was mounted on a poly-L-lysine-coated coverslip (coverslips were dipped twice in $41.6 \mathrm{ml}$ of $\mathrm{H}_{2} \mathrm{O}$ plus $25 \mathrm{mg}$ of poly-L-lysine plus $83.3 \mu \mathrm{l}$ photoflo and air dried after each coating), put through an EtOH dehydration series $(30 \%, 5 \mathrm{~min} ; 50 \%, 5 \mathrm{~min} ; 70 \%, 5 \mathrm{~min}$; and two times at $95 \%, 5$ min each), cleared in xylene (two times for 5 min each), and mounted on a slide with DPX mounting media (Fluka, Neu-Ulm, Germany). The slide was dried 1-2 d and visualized with a Bio-Rad 600 Confocal Microscope system equipped with a krypton-argon laser using the 488 and $568 \mathrm{~nm}$ lines. Filters used were a 560 DRLP dichroic, and 522 DF35 and 585 LP emission filters. The slide was mounted on a Zeiss (Oberkochen, Germany)Axiovert10 microscope equipped with oil immersion objectives $(16-100 \times)$. Digitized data were stored on zip drives and manipulated with NIH Image and Adobe Photoshop software. Steps through an entire ganglion were usually $4-5 \mu \mathrm{m}$ apart, whereas highmagnification steps through the STG, nerves, and neurons were usually $0.5-2 \mu \mathrm{m}$. The thickness of slices was estimated for all objectives by measuring 2, 3, and $15 \mu \mathrm{m}$ fluorescent beads under coverslips at the appropriate aperture and step settings. The depth of an optical slice ranged from 0.5 to $13.3 \mu \mathrm{m}$ and is indicated in the figure legends.

The same protocol was used for coarsely sectioned ganglion $(\sim 200 \mu \mathrm{m}$ sections), except that the tissue was sectioned after fixation. The same protocol was used for double-labeling experiments, except that the primary antibody solution included a mouse monoclonal anti-acetylcholinesterase (AChE) antibody $[10 \mu \mathrm{g} / \mathrm{ml}$ (Chemicon, Temecula, CA)], and the secondary antibody solution contained $1 \mu \mathrm{l}$ each of two different secondary antibodies, such that a combination of anti-mouse and anti-rabbit antibodies was present, each with a different fluorescent tag.

The protocol was modified slightly for isolated neurons. These were placed on a slide before fixation. The usual protocol was then performed with an $\sim 10$-fold reduction in incubation times. Pools of solutions were placed on top of the cells and incubated at room temperature without shaking. After washing out the secondary and just before the dehydration series, the cells were stained with propidium iodide by exposing the cells to a solution of $10 \mu \mathrm{g} / \mathrm{ml}$ propidium iodide (Molecular Probes) for $5 \mathrm{~min}$. The propidium iodide was washed out with several changes of PBS over a $2 \mathrm{hr}$ period. The previously described EtOH dehydration series, clearing, and mounting steps were then performed.

To demonstrate that the staining pattern in ganglia, nerves, and isolated cells represented lobster channel distribution, we always performed parallel controls in which the primary antibody was omitted, or the antibody was preabsorbed with the appropriate Shaker or Shal fusion protein, or the parental GST protein. When the primary antibody was omitted, none of the structures in the stomatogastric nervous system showed significant staining, except the central core of the stomatogastric nerve (stn) and some non-neuritic elements in the pyloric dilator (PD) nerve (pdn). Preabsorption of anti-Shal with the lobster Shal peptide or anti-Shaker with the lobster Shaker peptide blocked antibody staining. However, preabsorption of either antibody with the GST tag did not block staining. In addition, three additional lobster anti-Shaker antibodies (AS2, AS3, and AS4) were also used in ICC experiments with whole-mount preparations of the STG. The results were similar to those obtained with the initial anti-Shaker antibody described in Results (data not shown).

Quantitation of anti-Shal staining intensity. Staining intensity was semiquantitatively measured with the NIH Image program on a Macintosh computer (Apple Computers, Cupertino, CA). The freehand tool was used to draw circles around identified pyloric neurons at the point at which the diameter of the soma was largest and the membrane was most intensely stained. Cells were then cut out with the scissor tool and removed to a new NIH worksheet. A single representative slice was taken for each identified neuron. All identified cells from one ganglion were placed on the same worksheet and manipulated in an identical manner. The density slice tool was enabled, and the integrated optical density for each of the cells was determined. We estimated that the cytoplasmic contribution made up $\sim 5-10 \%$ of the total immunoreactivity in all cells examined (see Figs. $2 D$, $4 A$ ). In most cases, we did not observe significant differences in cytoplasmic staining between cells in the same ganglion. Staining intensity was normalized for each ganglion by dividing all cells for a particular ganglion by the cell having the highest integrated density for that ganglion. Thus, relative intensities for individual cells ranged from a maximum of one to a minimum that asymptotically approached zero. The magnification was such that glial and neuronal contributions to the anti-Shal ring could not be distinguished. If we assume that the glial contribution per square micrometer of membrane surface is constant, then our method introduces two errors into our measurements. First, the glial contribution will have a greater weight in neurons with fewer Shal channels relative to cells with a higher number of Shal channels. This technical artifact would reduce the slope of the best-fit line shown in Figure $4 B$. We have not controlled for this error. The second error stems from the fact that the total number of glia around larger neurons is greater than for smaller neurons. Thus, if two different size neurons have the same number of Shal channels in their membrane, the larger neuron will always receive a higher value for staining intensity by virtue of its glial component. To compensate for this artifact, we normalized staining intensity by average cell size using our previous measurements of average membrane capacitance for each cell type (Baro 


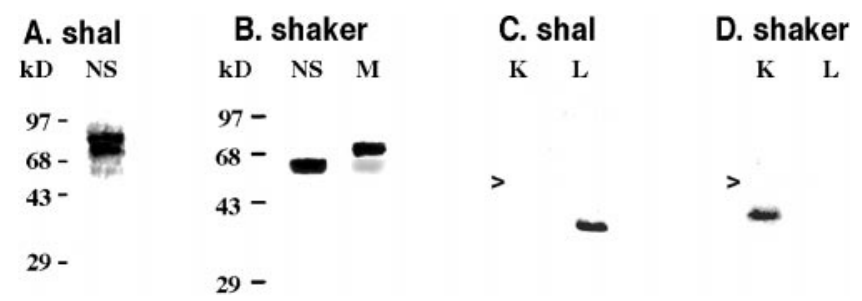

Figure 1. Anti-Shal and anti-Shaker specifically recognize their respective proteins. Western blots containing protein extracts from the lobster nervous system $(N S)$ and tail muscle $(M)$ were probed with anti-Shal $(A)$ or anti-Shaker $(B)$ antibody. The molecular weight standards for each Western blot are indicated. Western blots containing in the $16.7 \mathrm{kDa}$ pinpointShaker $(K)$ and the $15.2 \mathrm{kDa}$ pinpoint-Shal $(L)$ fusion proteins were probed with anti-Shal $(C)$ and anti-Shaker $(D)$ antibodies. The arrows point to the position of the $28 \mathrm{kDa}$ GST protein.

et al., 1997). Other uncontrolled variables that might influence the data in a nonsystematic manner include the following. (1) Only a subset of the 14 pyloric neurons was identified in any given experiment; thus, the most intensely stained cell could change in some experiments, because a cell was absent. This could result in different relative values being assigned to the same neuron, depending on which cells were identified; however, the rank order of staining would be retained. (2) The glial contribution could vary between cells depending on exactly where we drew the boundary. We expect that this will affect all cell types in a like manner, and so should not affect the average relative values we present, but it will increase the variation seen within a cell type. Because our method is only semiquantitative, we emphasize that the values we report should not serve as an accurate measurement of protein in each cell type.

\section{RESULTS}

\section{Preparation and characterization of antibodies}

An affinity-purified rabbit polyclonal antibody (anti-Shal) was raised against 20 amino acids from a cytoplasmic region between the last membrane-spanning domain and the $\mathrm{C}$ terminus of the lobster Shal channel, as described in Materials and Methods. Transcripts from the lobster shal gene are alternately spliced to produce at least 14 different proteins that range in size from 500 to 677 amino acids, or $\sim 50-75 \mathrm{kDa}$ (D. Baro, unpublished observations). Anti-Shal should recognize 12 of the 14 lobster Shal isoforms, because the other two Shal isoforms lack an exon(s) that contains $70 \%$ of the antigen used in antibody production (Baro, unpublished observations). Similarly, an affinity-purified rabbit polyclonal antibody, called anti-Shaker, was raised against 34 amino acids from the cytoplasmic invariant region near the $\mathrm{N}$ terminus of the lobster Shaker channel. Kim et al. (1997, 1998) demonstrated that transcripts from the lobster shaker gene are alternately spliced to produce at least 16 proteins ranging in size from 510 to 548 amino acids ( $\sim 56-60 \mathrm{kDa})$. Anti-Shaker should recognize all of these lobster Shaker isoforms.

Each antibody was used to probe Western blots containing protein extracts from the nervous system or tail muscle (Fig. $1 A, B$ ), as well as lobster Shaker and Shal fusion proteins (Fig. $1 C, D)$. Figure $1 A$ demonstrates that anti-Shal recognizes a smear of proteins in nervous tissue whose sizes are consistent with those predicted from the Shal sequence data. Two sizes predominate, as evidenced by the two dark bands within the smear. Anti-Shal did not produce a detectable signal with protein extracts from the tail muscle (data not shown). Anti-Shaker, on the other hand, recognizes proteins in both nervous tissue and tail muscle (Fig. $1 B$ ). A single band of predicted size is detected in the nervous system, whereas two bands are detected in muscle tissue. The fainter muscle band corresponds in size to the nervous system isoform(s), but the predominant band is significantly larger than the predicted size of Shaker channels. This band may represent proteins with different post-translational modifications or an alternate splice form(s) of Shaker that we did not detect in our earlier studies. The anti-Shaker and anti-Shal preimmune sera did not recognize any of these lobster proteins or the fusion proteins (data not shown), and each antibody recognized only the appropriate fusion protein (Fig. $1 C, D$ ). Together, all of these data indicate that anti-Shal and anti-Shaker are capable of specifically detecting lobster Shal and Shaker channels, respectively. Thus, we used these antibodies to examine Shal and Shaker channel distributions in the STG.

\section{The architecture of the STG}

The structure of the STG has been well defined at both the light and electron microscopic (EM) levels (Maynard, 1971a,b; Friend, 1976; King, 1976a,b; Baldwin and Graubard, 1995; Kilman and Marder, 1996; Christie et al., 1997) and is diagramed in Figure 2, $A$ and $B$. There are two major nerves associated with the ganglion: the stomatogastric nerve (stn) extending down from higher nervous centers, and the dorsal ventricular nerve (dvn) extending out to the pyloric musculature around the foregut. A perineural sheath covers the ganglion and its associated nerves. The STG is comprised of a core of neuropil surrounded by an outer shell called the peripheral zone, which contains neuronal cell bodies, nerve fibers, blood vessels, and blood cells interspersed among numerous glial elements (Friend, 1976; King, 1976a,b). The neuropil can be subdivided into at least two regions. The central coarse neuropil contains the large lower branch order neurites and few synapses, whereas the more peripheral fine neuropil contains the fine higher branch order processes and the majority of synapses (King, 1976a; Baldwin and Graubard, 1995). There are $~ 30$ neurons in the STG, 14 of which belong to the pyloric network. A primary neurite extends from the soma into the coarse neuropil, whereupon it branches into secondary and tertiary processes that extend toward the periphery of the ganglion. These processes project to specific regions of the fine neuropil in which they branch and synapse extensively (Baldwin and Graubard, 1995).

\section{Channel distribution in the STG peripheral zone: Shal, but not Shaker, channels are inserted in the membranes of the somata and initial neurites}

Confocal imaging of Panulirus STG whole mounts that were stained with either anti-Shaker or anti-Shal revealed that both antisera labeled the peripheral zone (Fig. $2 C-F$ ). Shaker channels were obvious in glial membranes ( $n=22$ STG). Previous EM studies indicate that the soma and primary process of a stomatogastric neuron are surrounded by a glial sheath ranging in thickness from $\sim 0.33$ to $5 \mu \mathrm{m}$. The sheath is made up mostly of thin glial processes, as well as an occasional glial soma sandwiched between these processes (Friend, 1976; King, 1976a,b). The anti-Shaker profiles reveal that the diameter of this sheath is relatively constant around a single neuron (Fig. 2C,E). The punctate anti-Shaker staining pattern throughout the sheath suggests a clustered distribution of Shaker channels in glial processes. Based on these data, we cannot determine whether or not Shaker channels are also located in the neuronal membrane.

The anti-Shal profiles suggest that Shal channels are in both the neuronal and glial somatic membranes; however, they are not abundant in glial processes (Fig. $2 D, F)(n=24$ STG). When stained with anti-Shal, the glial sheath appears asymmetric because the glial somata stain intensely, whereas the glial processes between, above, and below the somata do not show significant staining (Fig. 2F). This is most obvious along the sides and at the base of the neuronal cell body shown in Figure $2 F$ in which the many layers of thin glial processes making up the entire thickness of the sheath are nearly invisible (Fig. 2, compare $E, F$ ). Arrows point to stained glial somata in the glial cap of a second neuron that is ventrolateral to the neuron shown. The entire space between the glial somata and the somatic membrane of the neuron shown contains glial processes that are only slightly stained (Fig. 2, compare $C, E, F)$, suggesting that Shal channels are very diffusely distributed in the cytoplasm and/or membranes of glial processes. The neuronal membrane, on the other hand, stains intensely. The thickness of the anti-Shal line varies and often appears absent at certain points around the neuronal cell body. This may reflect imaging artifacts or the clustering of A-channels that has been reported to occur in invertebrate neurons (Premack et al., 1989).

At high magnification, we observed punctate anti-Shal staining in 


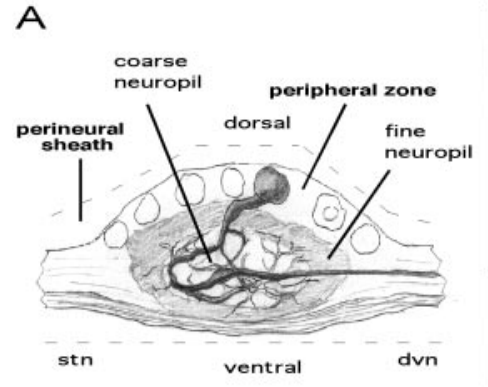

B

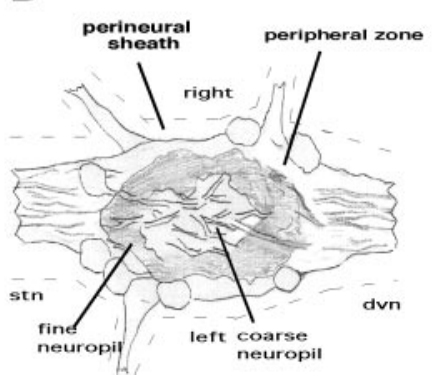

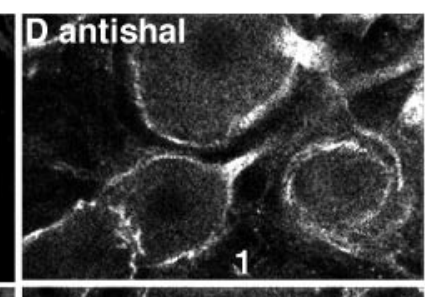
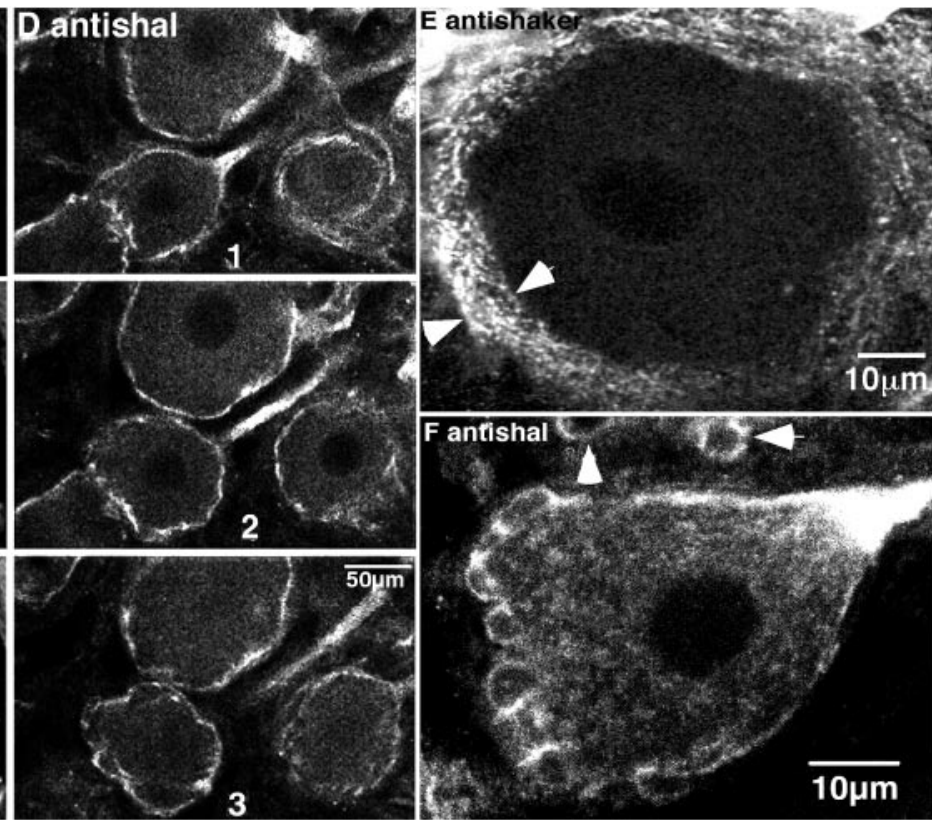

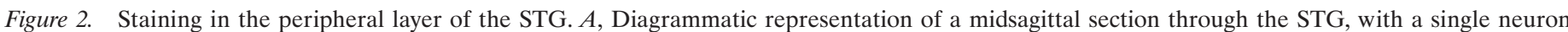

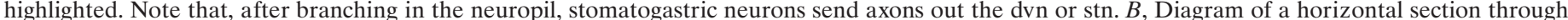

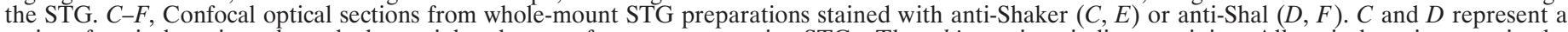

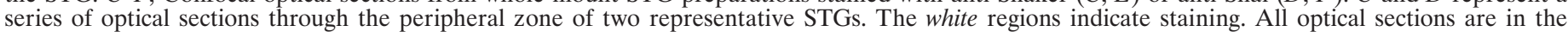

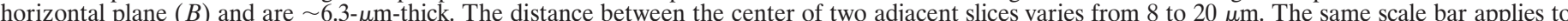

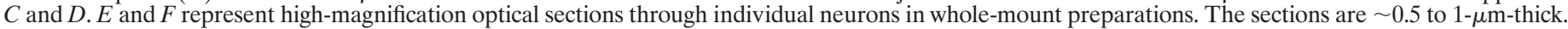
The arrows in $E$ define the thickness of the sheath. The arrows in $F$ point to glial somata in the cap of a neighboring neuron.

the somatic cytoplasm and a slight ring around the nucleus (Fig. $2 F)$. This most likely represents staining in the endoplasmic reticulum, Golgi stacks, and/or cargo vesicles. Anti-Shal also stained all primary neurites as they left the soma with $71 \pm 17 \%$ (SD, $n=6$ ganglia) showing strong cytoplasmic staining (Fig. $2 D, F$ ). It is interesting that the cytoplasm of the primary neurite, but not the somatic cytoplasm, was intensely stained with anti-Shal. These findings are consistent with EM studies showing that the cytoplasm is differentiated between the soma and the primary process such that there is an abrupt transition from dense (somatic) to clear (neuritic) cytoplasm (King, 1976a). Anti-Shaker did not obviously stain any structures in the somatic cytoplasm, nor did it stain the primary neurites.

To determine whether Shaker channels were present in neuronal as well as glial membranes and to confirm that Shal channels were present in the neuronal membrane, we performed experiments in which we removed the glial cap as described previously (Baro et al., 1996b). Figure 3 displays optical sections through two physically isolated neurons whose glial caps were removed before isolation. After isolation, the neurons were placed on slides and stained with propidium iodide, which stains nuclei red, and anti-Shal or antiShaker, which stain their respective potassium channels green. It is evident that glial cells were successfully removed because there are no red glial nuclei surrounding a neuron. The membraneassociated anti-Shal stain is still present when the glial cells are removed $(n=7)$, but the membrane-associated anti-Shaker stain is not $(n=14)$. Thus, Shal but not Shaker channels are located in the somatic membrane of stomatogastric neurons.

Anti-Shal staining intensity varied among cells. Presumably, this reflects differences in the abundance of Shal proteins in the somatic membranes of different neurons. If this is true, then cells with larger $I_{\mathrm{A}}$ amplitudes should have more intense anti-Shal rings relative to cells with smaller $I_{\mathrm{A}}$ amplitudes. To test this prediction, we electrophysiologically identified individual pyloric neurons and drew a map of their location in the ganglion. After identification, we filled two nonpyloric neurons with 5,6-carboxyfluorescein so that we could reorient the ganglion to the map after the ICC protocol. We then fixed and processed the ganglion for anti-Shal

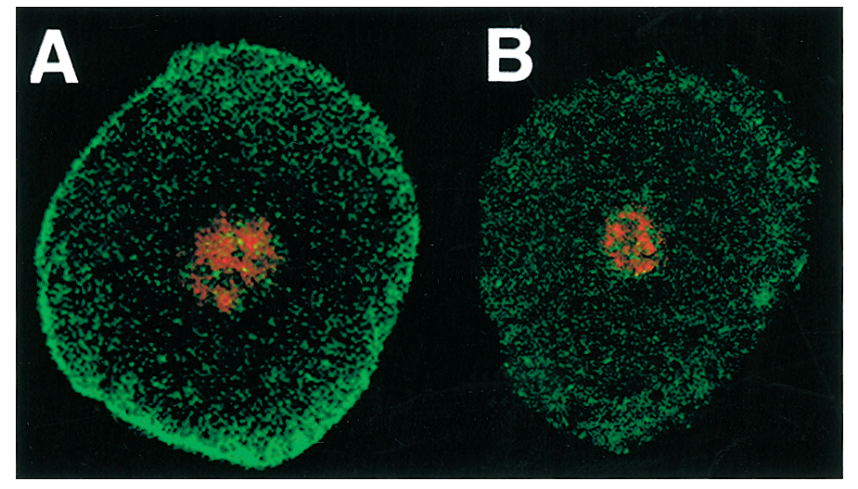

Figure 3. Shal but not Shaker channels are found in the membranes of neuronal somata. Horizontal optical sections through two physically isolated neurons lacking glial caps. Neurons were stained with anti-Shal $(A)$ or anti-Shaker $(B)$ and with propidium iodide. Propidium iodide stained the nuclei $r e d$, whereas channel antibodies stained green. Slices are $\sim 1 \mu \mathrm{m}$ thick.

ICC and confocal microscopy. Figure $4 A$ is an optical section from one such experiment. Five of the 14 pyloric neurons are observed in this optical section: both PD neurons, two of the eight pyloric constrictor (PY) neuron, and the single ventricular dilator (VD) neuron. We previously measured pyloric $I_{\mathrm{A}}$ amplitudes with twoelectrode voltage clamp from the soma (Baro et al., 1997). Hartline et al. (1993) have shown that channels in the soma and monopolar neurite are responsible for the measured currents, with little contribution from channels in the unclamped distal neurites; thus, we refer to these currents as somatic $I_{\mathrm{A}} \mathrm{s}$. The average size of the somatic $I_{\mathrm{A}}$ for these cell types is listed in Figure $4 A$ as the corrected maximal conductance (Gmax), which represents the A-channel conductance when all of the A-channels in the soma and proximal neurites are open (Baro et al., 1997; Willms et al., 1999).

As anticipated, cells with larger somatic $I_{\mathrm{A}}$ amplitudes appeared to have a more intense anti-Shal ring. Using the NIH Image program, we quantified the relative amounts of anti-Shal staining in 
A
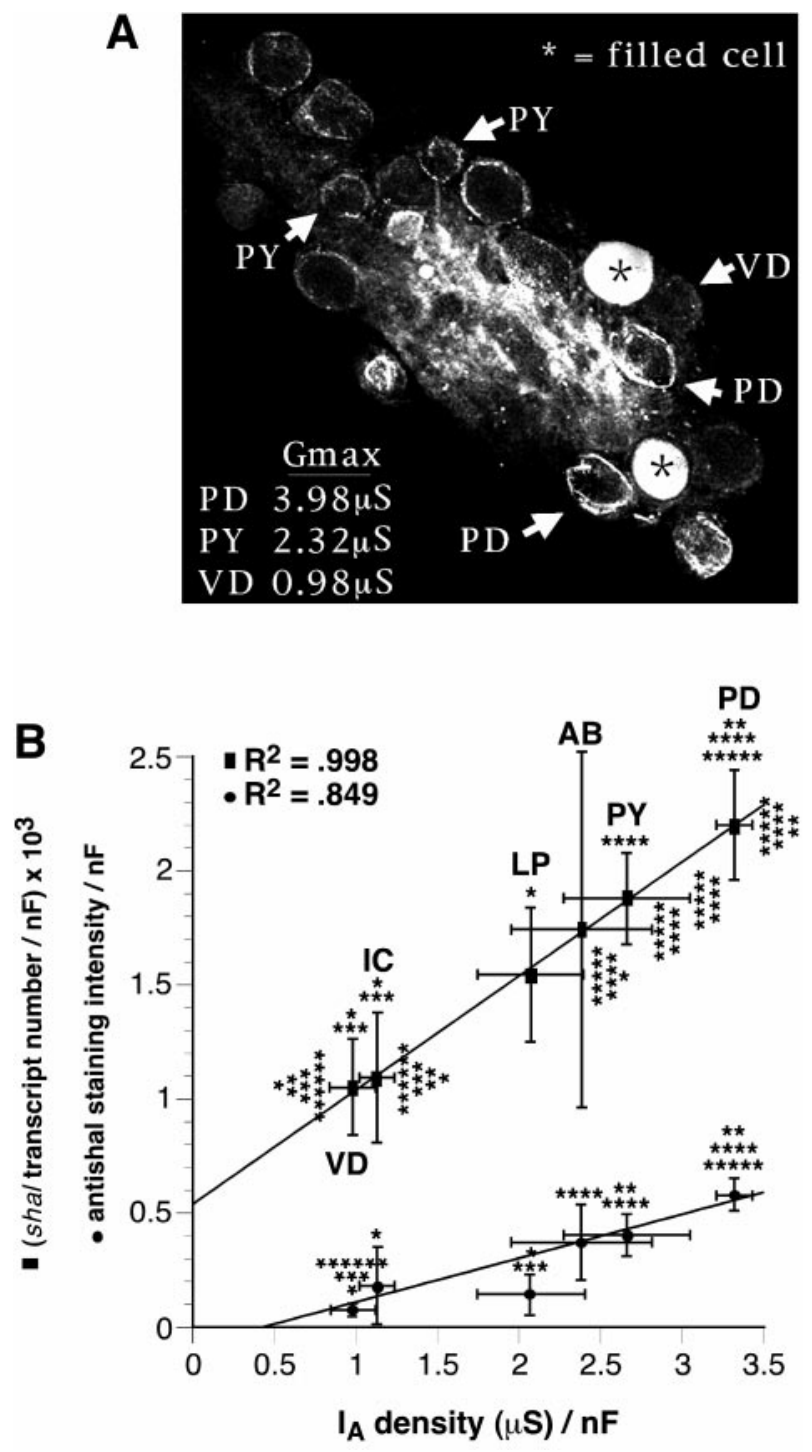

Figure 4. The density of shal transcripts, Shal channels, and somatic $I_{\mathrm{A}} \mathrm{s}$ are all linearly correlated in pyloric neurons. $A$, Representative horizontal optical section from an anti-Shal-stained whole-mount STG preparation in which neurons were electrophysiologically identified before ICC. Two nonpyloric neurons were filled with 5,6-carboxyfluorescein to orient the ganglion to the map after the ICC protocol. Optical slices were $\sim 13.3-\mu \mathrm{m}$ thick. $B$, The mean protein immunofluorescence (circles) and the average number of Shal transcripts (squares) for each cell type were first normalized by membrane capacitance and then plotted against the average maximal $I_{\mathrm{A}}$ density in that cell type. $I_{\mathrm{A}}$ density is defined as the average corrected Gmax divided by membrane capacitance (Baro et al., 1997; Willms et al., 1999). All statistical analyses were performed after dividing the data by membrane capacitance. Error bars represent SEs. Lines represent linear regressions of all data points (transcript density) or all data points excluding the LP (staining density). The cell types and the number of cells in each cell type are as follows: $P D, 2 ; V D, 1 ; P Y, 8 ; A B$, anterior burster, $1 ; I C$, inferior cardiac, $1 ; L P, 1$. The number of cells used to determine average staining intensity, transcript number, corrected maximal conductance, and membrane capacitance respectively, were as follows: $P D, 15,9,5,10 ; V D, 9,8,5$, $5 ; P Y, 22,14,7,10 ; A B, 4,4,5,3 ; I C, 6,6,5,3 ; L P, 6,6,7,7$. The data on transcript number, corrected maximal conductance, and membrane capacitance were taken from Baro et al. (1997). Significantly different $(p<0.05)$ than ${ }^{*} \mathrm{PD}, * * \mathrm{LP}, * * * \mathrm{PY}, * * * \mathrm{VD}, * * * * * \mathrm{IC}$, and $* * * * * \mathrm{AB}$, as judged by two-tailed $t$ tests.

the somata of identified pyloric neurons, as described in Materials and Methods. We then normalized the staining intensity by average cell size using our previous measurements of membrane capacitance (Baro et al., 1997). Figure $4 B$ is a plot of the average relative anti-Shal density versus the average $I_{\mathrm{A}}$ density for each cell type. We also plot our earlier data on the average number of shal transcripts in each cell type normalized by cell size (Baro et al., 1997). In both plots, there are statistically significant differences between cell types, and $I_{\mathrm{A}}$ amplitude linearly correlates with the Shal variable on the $y$-axis, suggesting that shal gene expression determines the density of the somatic A-channels in pyloric neurons. One neuron, the lateral pyloric (LP), did not fit on the linear relation for anti-Shal staining and was not included in the regression analysis. There are several possible reasons for this finding (see Discussion). The relationship between anti-Shaker staining intensity and $I_{\mathrm{A}}$ amplitude was also examined, and we found no quantitative differences between pyloric neurons (data not shown).

The quantitative measurements of staining density strengthen our hypothesis that anti-Shal staining around a pyloric cell mainly reflects channels in neuronal and not glial membranes. If the anti-Shal ring were mostly glial in nature, then we would not observe significant differences in anti-Shal density between cell types because the average number of glial cells per unit area should be constant for all cell types. Additionally, anti-Shal density would not correlate with pyloric $I_{\mathrm{A}}$ density, because the number of Shal channels in the glial cells surrounding a neuron should not reflect the $I_{\mathrm{A}}$ density in that neuron. The idea that Shal channels are in the neuronal membrane is further supported by the following facts: (1) anti-Shal membrane-associated staining remains when the glial cap is removed; (2) shal transcript number also varies linearly with somatic $I_{\mathrm{A}}$ density in pyloric neurons (Baro et al., 1997); and (3) when expressed in Xenopus oocytes, lobster shal cRNA produces an $I_{\mathrm{A}}$ that resembles pyloric $I_{\mathrm{A}} \mathrm{s}$ (Baro et al., 1996a). Similarly, the idea that Shaker channels are not found in the somatic membrane of the neuron and do not contribute to the somatic $I_{\mathrm{A}}$ is supported by the following facts: (1) anti-Shaker density does not vary with cell type; (2) staining is lost when the glial cap is removed; and (3) when expressed in Xenopus oocytes, lobster Shaker cRNA does not produce an $I_{\mathrm{A}}$ that resembles pyloric $I_{\mathrm{A}} \mathrm{s}$ (Baro et al., 1997). Together, all of these data provide compelling evidence that shal, but not shaker, underlies the somatic $I_{\mathrm{A}}$ in pyloric neurons, as is the case in other systems (Tkatch et al., 2000).

\section{Channel distribution in the STG neuropil: Shal, but not Shaker, channels can contribute to firing properties arising from the neuropil compartments}

Thus far, our findings suggest that Shal channels contribute to the firing properties that arise from, or are influenced by, the soma and initial neurite. However, many firing properties are determined in cellular compartments that lie outside these regions. To establish which channels contribute to these properties, we first examined Shaker and Shal distribution in the neuropil. Figure 5 demonstrates that all anti-Shal staining is in or immediately adjacent to neuritic processes throughout the neuropil (Fig. $5 A-F$ ), whereas antiShaker does not stain the neuropil (Fig. $5 G, H$ ).

The neuropil is comprised of neurites of varying dimensions with glia and other non-neuritic elements tightly packed into the entire space between neurites (Friend, 1976; King, 1976a,b). Figure $5 B-F$ demonstrates that anti-Shal heterogeneously stained the neuritic cytoplasm throughout the coarse and fine neuropil, but in those neurites in which cytoplasmic staining was low or absent, the anti-Shal stain often appeared as two lines on either side of the process ( $n=22$ STG). The lines of staining have the same dimensions and characteristics as the plasma membranes seen in Figures 2 and 3, and they follow the neurite exactly. Thus, the lines are likely to reflect the insertion of Shal channels in the neuritic membrane. This interpretation agrees with physiological studies showing that $I_{\mathrm{A}}$ can alter bursting and spike frequency, properties widely believed to arise in the neuropil (Hartline, 1979; Tierney and Harris-Warrick, 1992; Harris-Warrick et al., 1995a,b).

Similar to the situation in the peripheral layer, Shal channels may be present in the somatic membranes of presumptive glial cells in the neuropil (Fig. 5C); however, we could not distinguish between small blood vessels and glial somata at the light level, both of which are present in the neuropil and have approximately the same dimensions (King, 1976a). Although Shal channels are not obvi- 
Figure 5. Shal, but not Shaker, channels mediate the $I_{\mathrm{A}}$ in the neuropil. Shown are horizontal optical sections from various STG whole-mount preparations stained with anti-Shal $(A-F)$ and anti-Shaker $(G)$, or an anti-Shaker-stained cross-section of the STG $(H)$. A, An optical section from the center of the ganglion showing the peripheral zone (somata) encircling the layer of fine neuropil, which surrounds the coarse neuropil. Note that large processes are outlined in the central coarse neuropil and that tufts of fine neuropil along the periphery are intensely stained. The thickness of the slice is $\sim 13.3 \mu \mathrm{m}$. $B$, Higher magnification of the coarse neuropil showing a primary neurite with intense cytoplasmic staining, and higher order neurites with variations in the staining of the cytoplasm and the membrane. The slice thickness is $\sim 6.3 \mu \mathrm{m}$. $C$, High magnification of a neurite from the coarse neuropil; arrowheads point to presumptive glial somata or blood vessels adjacent to the neurite. The thickness of the slice is $\sim 1 \mu \mathrm{m}$. $D$, Projection of six optical sections, spanning $\sim 6-8 \mu \mathrm{m}$ in depth, showing the variation in membrane staining intensity in neighboring neurites. Also note the lack of glial staining between neurites and the lack of glial somata. $E$, Optical cross-sectional view through the neuropil of a ganglion. Tracts of glia and large neurites separate the fine neuropil. Note that the anti-Shal stain encircles small fibers in the V-shaped regions of synaptic neuropil. Larger processes separating the fine neuropil are also outlined and some show cytoplasmic staining. The slice is $\sim 6.3-\mu \mathrm{m}$-thick. $F$, High magnification of the fine neuropil; note the amorphous mesh-like structure of this anti-Shal
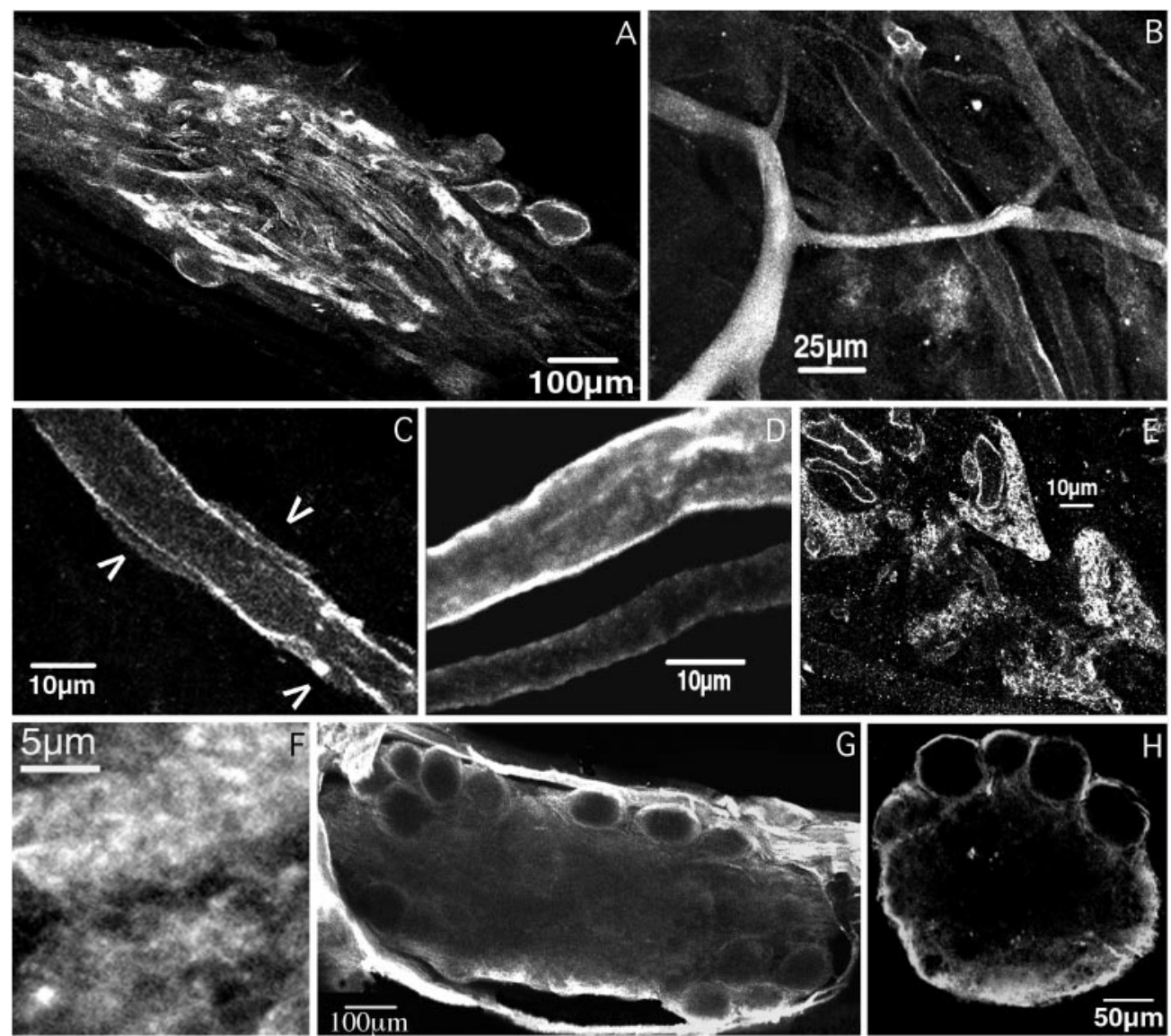

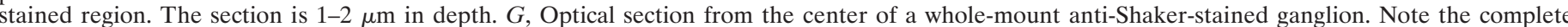

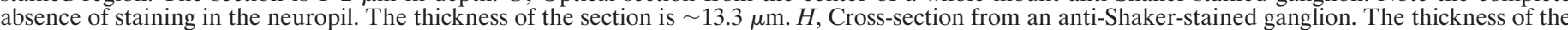
optical section is $6-8 \mu \mathrm{m}$. Note that the most intensely stained structure is the perineural sheath along the sides and bottom of the ganglion.

ously in glial processes in the neuropil, we cannot rule out the idea that the lines of anti-Shal immunoreactivity reflect Shal channels in very thin glial processes immediately adjacent to the neurite. However, this seems unlikely and would require that the glial sheath that fills the space between two neurites be made up of a variety of glial cells, a few with very specialized labeled processes abutting the neurites. In addition, targeting of Shal channels would have to change in the neuropil, relative to the peripheral layer, such that Shal channels would be enriched in the glial processes of these cells. Finally, because some clearly outlined neurites display no adjacent glial somata for greater than $60 \mu \mathrm{m}$ (Fig. 2D), the specialized glial processes would need to be at least that long. Although specialized glial cells were not described in previous EM studies on the Panulirus STG (Friend, 1976; King 1976a,b), we cannot rule out this interpretation. However, we feel the most parsimonious explanation of the data is that Shal channels are found in the membranes of both neurites and neuroglia, but in the case of neuroglia, most staining is limited to the soma.

In the fine neuropil, the thickness of the glial sheath decreases to zero (Friend, 1976; King, 1976a,b). Although the non-neuritic material in the fine neuropil is dramatically reduced compared with the coarse neuropil, the anti-Shal staining intensity is always greater in the fine neuropil (Fig. $5 A$ ). Figure $5 E$ provides a crosssectional view of the fine neuropil. The synaptic neuropil is subdivided into smaller $\mathrm{V}$-shaped regions by the intrusion of thick layers of glia, groups of large fibers extending out from the coarse neuropil, and blood vessels. Anti-Shal immunoreactivity did not stain the thick glial layers but did encircle the obtruding coarse neurites and the larger processes in the fine neuropil $(1-4 \mu \mathrm{m})$. In some instances, it was also possible to observe anti-Shal stain encircling neurites $<1 \mu \mathrm{m}$ in diameter, but usually the processes were so small and dense that individual fibers could not be resolved. In- stead, the finest neuropil appeared as delicate white clouds (Fig. $5 F$ ). Similar cloud-like structures were seen with an antisynaptotagmin primary antibody that exclusively stains neuropilar synapses (J. P. Mackler and K. Graubard, unpublished observations).

In contrast to anti-Shal, anti-Shaker does not detectably stain any structures in the neuropil of whole-mount preparations (Fig. 5G) $(n=17)$. This is not an antibody penetration problem because, as shown in Figure $5 H$, we see no anti-Shaker staining in the neuropil of ganglia that had been physically cross-sectioned before being processed for anti-Shaker ICC $(n=5)$. Even at high magnification, Shaker channels are not detectable in the neurites, nor are they obviously present in the glial cells within the neuropil. Because Shaker channels appear to be present in the glial cells surrounding the neuronal somata (Fig. 2), their absence in the neuropil suggests that different neuronal compartments possess distinct glial elements.

These data indicate that shal encodes the A-channel $\alpha$-subunits in the neuropil and that shaker does not. The complete absence of Shaker channels in the soma and neuropil suggest that shaker gene expression cannot influence any firing properties or synaptic interactions occurring in these regions. However, because the shaker gene is known to be expressed in all pyloric neurons (Baro et al., 1996b), perhaps it could contribute to the excitable properties of the axonal compartment.

\section{Channel distribution in stomatogastric nerves: Shaker channels appear to be inserted into axonal and glial membranes, whereas Shal channels are mainly found in the axoplasm}

The STG is an integral part of the STNS, which generates and coordinates the movements of the entire crustacean foregut. As shown in Figure $6 A$, when a pyloric motor axon leaves the STG, it 
A
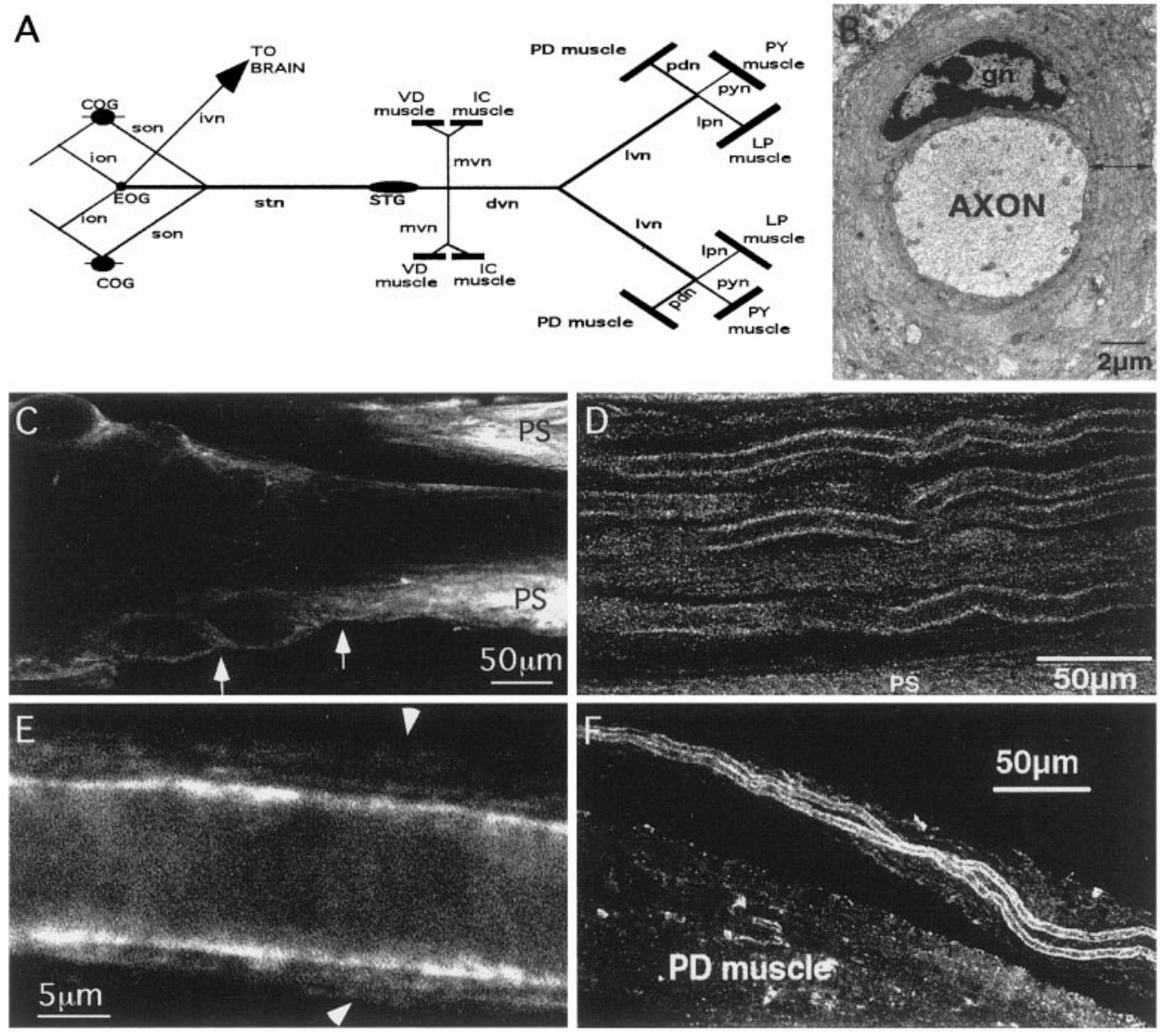

Figure 6. Anti-Shaker is found in axonal compartments located in the nerves of the STNS. A, Diagram of the STNS. Lines represent nerves, filled ovals represent ganglia, and rectangles represent muscles. $C O G$, Commissural ganglion; $E O G$, esophogeal ganglion; ion, inferior esophogeal nerve; son, superior esophogeal nerve; lpn, lateral pyloric nerve; pyn, pyloric constrictor nerve; $I C$, inferior cardiac. $B$, Electron micrograph of STNS axon with surrounding glial sheath; we gratefully acknowledge that the EM photograph was a kind gift from Dr. David King. gn, Glial cell nucleus. Line with double arrowheads shows the thickness of the glial wrap at one point tangential to the axon. $C$, Horizontal optical section (13.3- $\mu$ m-thick) from the center of a representative antiShaker-stained ganglion-dvn showing the emergence of the dvn from the STG. Arrows approximate the preaxon region (between the end of the neuropil and the beginning of the dvn). Note that the lack of anti-Shaker staining in the neuropil processes continues as the processes leave the ganglion and enter the dvn, whereas the perineural sheath $(P S)$ is brightly stained. $D$, Horizontal optical section from the distal region of an anti-Shakerstained dvn. Note the continuous stain along the edges of large axons in the plane of focus and the fainter staining in the surrounding glial sheaths when they are in the plane of focus. The faintly stained bundle of small-diameter axons is seen just below center. The optical section is $\sim 6$ to 8 - $\mu$ m-thick. $E$, High magnification of a single process and the surrounding glial sheath from an anti-Shaker-stained lvn. Arrows mark the outer bounds of the glial sheath. The thickness of the optical section is $\sim 0.5 \mu \mathrm{m}$. $F$, Anti-Shaker stained PD nerve, which contains only the axons from the two PD neurons, approaching the PD muscle. The section is $\sim 6$ to 8 - $\mu$ m-thick. travels distally through the dvn and either the lateral ventricular nerves (lvns) or the medial ventricular nerves (mvns), before entering a terminal motor nerve, like the pdn. A terminal motor nerve exclusively contains axons from a single cell type of the given name and innervates the appropriate pyloric muscle of the same name. The dvn contains $\sim 35-45$ large processes ranging from 3 to $8 \mu \mathrm{m}$ in diameter and a bundle of small diameter fibers $(<0.5 \mu \mathrm{m})$. King (1976a,b) demonstrated that Panulirus axons are not myelinated but that thick glial sheaths individually encase each of the large processes in a nerve. Dr. David King (Southern Illinois University, Carbondale, IL) kindly provided us with an electron micrograph from his earlier studies (Fig. 6B), showing that many glial cells wrap around an individual axon, forming a series of concentric rings. Thin, irregular glial processes comprise most of the sheath with occasional glial somata sandwiched between processes.

Figure $6 D-F$ suggests that Shaker channels are localized to the membranes of axons and glial processes in the dvn, lvn, and pdn. Near the point at which the dvn emerges from the STG, the anti-Shaker immunoreactivity appeared faint, and Shaker channels were not observed in most preaxonal and axonal membranes as they left the neuropil and entered the dvn (Fig. $6 C$ ). However, the anti-Shaker profile changed in more distal sections of the dvn and throughout the lvn, such that very distinct, intense lines appeared at the boundary between the axoplasm and the sheath of most processes (Fig. 6D,E). Additionally, anti-Shaker consistently outlined both PD axons as they traveled through the PD nerve (Fig. $6 F$ ). The dimensions and characteristics of the intense lines are consistent with those representing the plasma membranes in Figures $2 F$ and $3 A$. Consequently, we interpret these motor nerve staining patterns to mean that Shaker channels are present in distal axonal membranes and possess a clustered distribution as judged by differences in intensity along the anti-Shaker lines (Fig. 6E). Shaker expression patterns therefore divide these axons into two distinct subcompartments: proximal and distal. A similar situation has been described for metabotropic glutamate receptor expression in hippocampal axons (Stowell and Craig, 1999). Shaker channels also appeared to be present at lower concentrations in the glial sheath and the axoplasm (Fig. $6 D, E$ ). We should point out that anti-Shaker did outline some axons at the beginning of the dvn. However, those processes appeared to arise mainly from the peripheral layer or the perineural sheath rather than the neuropil. Furthermore, the stain was distinctly different from that seen in distal nerves in that it was faint and punctate and did not clearly separate the axoplasm from the sheath.

An alternative explanation of these data might be that, beginning in the distal regions of the dvn, the expression of the shaker gene is altered in glial cells whose processes are immediately adjacent to the axon, such that there is a dramatic increase in channel number. Again, this necessarily implies that multiple types of glia comprise the sheath, that the glial processes immediately adjacent to the neuron are highly specialized, and that the highly specialized glia in the axonal compartment express different channels in their processes than the highly specialized glia in the neuropil compartment. A third interpretation is that the characteristics of the glial wrap may change in distal regions of the nerve such that glial layers in close proximity to the neuron might be more highly compressed than outer layers. Previous EM studies did not note differences in the glial cells in different layers of the axonal sheath (King, 1976a,b), and the function of increased Shaker channels in glial processes abutting the axon is not obvious. Thus, we suggest that the most parsimonious interpretation of the data is that Shaker channels are in the axonal membrane as well as the glial membrane. Although further experiments are required to confirm this interpretation, it is consistent with findings in other systems (Wang et al., 1993; Rosenthal et al., 1996, 1997; Rogero et al., 1997) and the 
Figure 7. Immediately after branching in the neuropil, Shal channel density is dramatically reduced in most STG processes. $A-C$, Three representative ganglia and dvns stained with anti-Shal. Arrows approximate the preaxon region of the STG, and arrowhead points to the bipolar anterior gastric receptor cell located in the dvn. PS, Perineural sheath. A, Projection of six optical slices through the posterior portion of the STG and the beginning of the dvn. The projection represents $\sim 45$ $\mu \mathrm{m}$ in depth. Note the lack of staining outside of the neuropil. A few (pre-) axons were outlined in most ganglia ( $n=10$ STG), but for the most part, staining of the processes outside the neuropil was only slightly above background. $B, C$, Single optical sections from representative anti-Shal-stained ganglia and dvns. Sections are $\sim 13.3-\mu \mathrm{m}$-thick. $D$, Horizontal optical section from the distal portion of an anti-Shal-stained dvn. Note the heterogeneous staining of the axoplasm. Background levels of staining are varying from $A$ to $D$, and so the panels cannot be directly compared. The thickness of the section is $\sim 6 \mu \mathrm{m}$. $E$, High magnification of an axon from an anti-Shal-stained lvn. Note that anti-Shal does not outline the axon. The section thickness is $\sim 1 \mu \mathrm{m} . F$, Optical section from an anti-Shal-stained pdn showing a region in which the two PD axons are differentially stained with antiShal. Arrows point to the autofluorescent disk-shaped structures that were present throughout the entire pdn. The section is $\sim 1$ to 2 - $\mu$ m-thick.
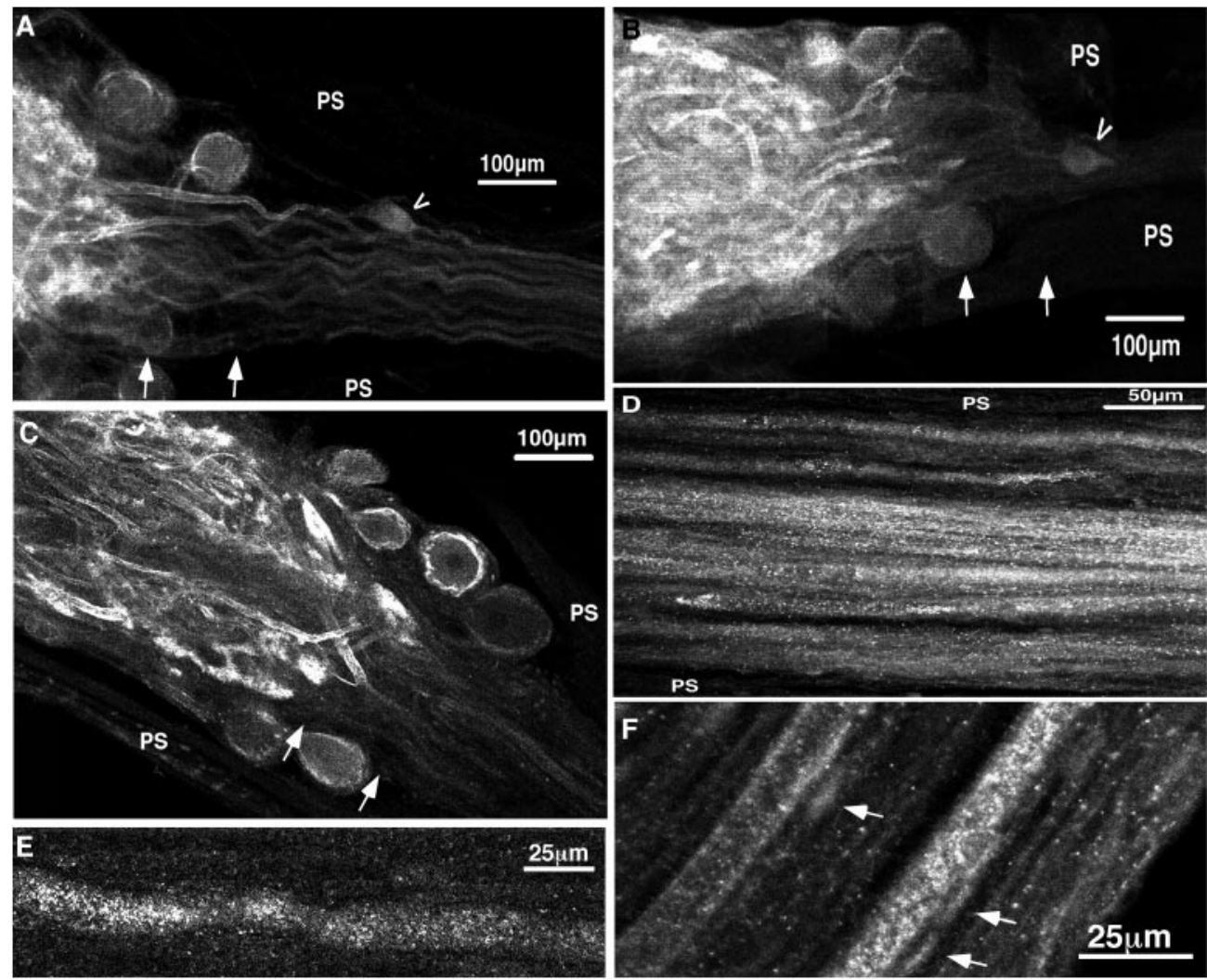

fact that all stomatogastric neurons express the shaker gene (Baro et al., 1996b).

As in other subcellular compartments, the anti-Shal profile differed from the anti-Shaker profile in motor nerves. Instead of outlining the axons, anti-Shal heterogeneously stained the axoplasm of most processes (Fig. 7). Whereas Shal channels clearly outlined neurites in the neuropil (Fig. 5), the anti-Shal staining pattern changed as the processes left the neuropil. Shal channels were no longer detectable in most membranes in the preaxon region, between the neuropil and the dvn. Instead, there was faint immunoreactivity in the axoplasm that continued as the axons left the STG and entered the dvn (Fig. $7 A-C$ ). Similarly, most antiShal-stained axons in the dvn and lvn were not demarcated by sharp continuous lines along their length as were the anti-Shalstained neuropil processes or the anti-Shaker-stained axons (Fig. $7 D, E)$. Even when single fibers were observed at higher power (Fig. $7 E$ ), the anti-Shal label displayed a punctate distribution throughout the fiber, suggesting that either Shal is not in the neuronal membrane or the axoplasmic concentration of channels is greater than or equal to the membrane bound concentration. AntiShal immunoreactivity in the pdn was very irregular. Staining could differ between the two PD axons in a given section of the pdn such that the axoplasm of one axon would be brightly stained, whereas axoplasmic staining in the second axon was weak or undetectable (Fig. $7 F$ ). However, one could also observe regions in which both axons demonstrated or lacked axoplasmic staining. When axoplasmic staining was absent, small patches of anti-Shal immunoreactivity were sometimes observed in the axonal membrane. In addition to staining these commonplace axonal elements, anti-Shal also stained unidentified placode-like structures in the axoplasm that were $\sim 10 \mu \mathrm{m}$ in length. The distribution of these structures appeared random and intermittent, and we did not characterize them further.

\section{Channel distribution at the neuromuscular junction: Shaker and Shal channels are specifically targeted to synaptic contacts}

The last morphologically distinct compartment within a pyloric motor neuron occurs at the neuromuscular junction (NMJ). To determine whether Shaker and Shal channels could participate in peripheral synaptic transmission, we examined their distribution at PD NMJs. The PD neuron is cholinergic (Marder, 1974, 1976); thus, a PD NMJ can be detected by the presence of AChE, which is highly concentrated in the synaptic cleft and junctional folds of cholinergic endplates. We examined channel distribution by performing double-label experiments on innervated PD muscle preparations, using our rabbit polyclonal antibodies and a mouse monoclonal antibody raised against the human form of $\mathrm{AChE}$ (anti-AChE).

Figure 8 shows that both Shaker and Shal channels colocalized with $\mathrm{AChE}$ at the PD NMJ and appeared as islands, or clusters, of tiny white dots. We measured the islands and found that their length and width (9-67 $\mu \mathrm{m}$ and 2-24 $\mu \mathrm{m}$, respectively) corresponded well with the dimensions of STG motor nerve terminals previously obtained from serial EM reconstructions (Atwood et al., 1977, 1978; Govind, 1979; Meiss and Govind, 1979) (for review, see Govind and Lingle, 1987). Furthermore, the average number of labeled dots per micrometer of terminal $(1 \pm 0.4)$ was very similar to the average number of synaptic contacts per micrometer of nerve terminal obtained from earlier EM studies [1.2-1.4 (Atwood et al., 1977; Patel and Govind, 1997a,b)]. Thus, these data suggest that the islands correspond to axon terminals, whereas the tiny dots correspond to individual synaptic contacts on the terminals.

The data further suggest that Shal and Shaker channels are specifically targeted to sites of synaptic contacts in the NMJ. The regions between clustered anti-AChE dots within an island represent nonsynaptic regions of a terminal on the muscle. If the channels were present throughout the terminal/muscle or in the glial elements covering these regions, the staining profiles would appear as long white structures whose dimensions reflected those of the terminals or muscle and not as a collection of dots. Instead, most $\mathrm{K}^{+}$channel staining colocalized with the punctate anti-AChE stain. Although EM studies are required to define the specific location of the channels, Atwood et al. (1977) demonstrated that glial cells are excluded from synaptic regions; thus, AChEcounterpart dots in the anti-Shaker and anti-Shal panels most likely represent channels in the muscle and/or nerve terminal. Using 

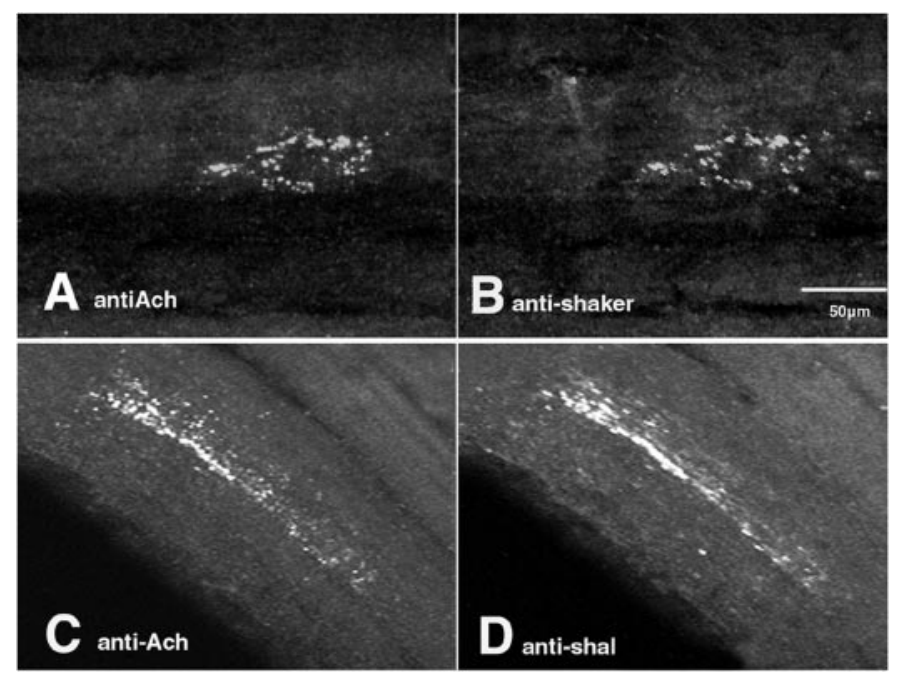

Figure 8. Shal and Shaker channels are targeted to the PD NMJ. A single optical section from an innervated PD muscle double-labeled with a mouse monoclonal antibody against acetylcholinesterase (antiACh;A) and our polyclonal anti-shaker $(B)$. Secondary antibodies were tagged with Oregon Green (anti-mouse) or Texas Red (anti-rabbit). Both fluorescent tags were concurrently imaged in all optical slices of a z-series through the NMJ. Optical section from a second PD muscle double-labeled with anti-AcH $(C)$ and anti-shal $(D)$. Imaging was as described for the previous panels. Optical sections are $\sim 0.5$ to $2-\mu \mathrm{m}$-thick.

reverse transcription (RT)-PCR, we found that both shal and shaker RNA are present in the PD muscle (data not shown); thus anti-Shaker and anti-Shal synaptic staining could represent neuronal and/or muscle channels.

\section{DISCUSSION}

The distinct firing properties of pyloric neurons are essential for their role in motor pattern generation. All neurons display spontaneous, rhythmic oscillations in membrane potential and bursts of spikes (Fig. 9). Because there is a burst of spikes within each oscillation and because these spikes trigger pyloric muscle contractions (Hooper, 1997a,b; Morris and Hooper, 1997, 1998), the oscillations in neuronal membrane potential underlie the rhythmic movements of the foregut. Figure 9 illustrates that each cell type has a unique electrical phenotype defined by the shape of the oscillation, the timing of the burst, and the number of spikes per burst. $I_{\mathrm{A}} \mathrm{s}$ help to shape these firing properties in pyloric neurons (Hartline, 1979; Graubard and Hartline, 1991; Hartline and Graubard, 1992; Tierney and Harris-Warrick, 1992; HarrisWarrick et al., 1995a,b). In the present study, we show that the $I_{\mathrm{A}} \mathrm{s}$ in the different subcellular compartments are mediated by different A-channels with distinct biophysical properties. This may reflect the fact that the currents serve different functions in each compartment.

\section{Shaker and Shal contribute to distinct firing properties within a single neuron}

A pyloric neuron can generate oscillations in membrane potential by multiple mechanisms (Harris-Warrick and Flamm, 1987). Although specific conductances have been implicated in the oscillations, their spatial distributions are not known, and the question of where the oscillation generator(s) lies is still open to debate (Gola and Selverston, 1981; Russell and Hartline, 1984; Graubard and Ross, 1985; Ross and Graubard, 1989; Graubard and Hartline, 1991; Golowasch and Marder, 1992; Kiehn and Harris-Warrick, 1992a,b) (for review, see Hartline and Graubard, 1992; Zhang and Harris-Warrick, 1995; Zhang et al., 1995; Hurley and Graubard, 1998). Most inward currents underlying the plateau properties that give rise to oscillations cannot be voltage-clamped from isolated somata; hence, it is generally thought that they are missing from the soma and that the soma may influence but not generate oscillations.
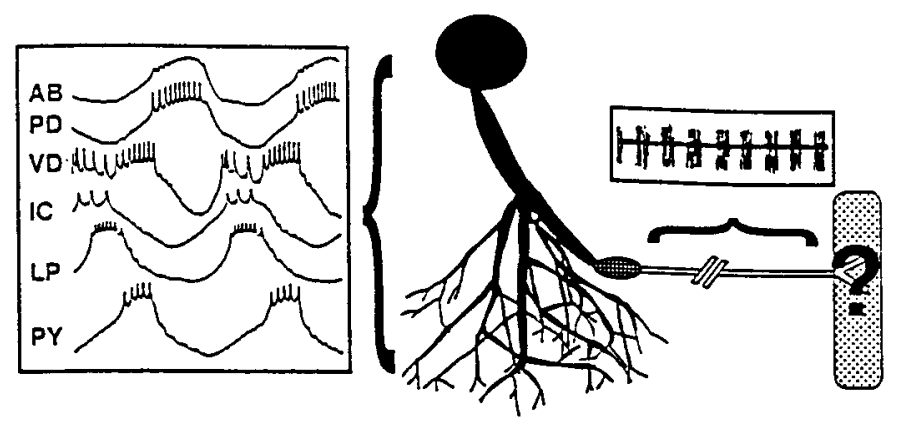

Figure 9. The functional implications of the differential compartmentalization of Shaker and Shal channels along a pyloric neuron. The diagram represents the PD neuron innervating the PD muscle. The shaded areas represent the regions of the neuron that contain membrane-bound Shal channels but no membrane-bound Shaker channels. The area corresponds exactly to the somatodendritic compartment, which lies in the peripheral layer and neuropil of the STG. The box positioned next to the neurites contains spontaneous, simultaneous intracellular recordings from the somata of each of the six identified pyloric cell types (Miller, 1987). Shal, but not Shaker, channels contribute to the large, rhythmic oscillations in membrane potential that are generated in, and influenced by, the somatodendritic compartment. The circle with the grid represents the region in which membrane-bound Shaker and Shal channels are not detectable. This region most likely contains the initial segment molecular fence that prevents diff usion of membrane proteins (Winckler and Mellman 1999; Winckler et al., 1999). The primary spike initiation zone might lie in, or immediately proximal to, this region, suggesting that somatodendritic Shal channels primarily mediate the effect of the $I_{\mathrm{A}}$ on spike timing and frequency. The unshaded area represents the region in which membrane-bound Shaker channels predominate. This region corresponds to the distal axonal compartment located in stomatogastric nerves. A typical extracellular recording from this compartment is shown above the axon. Shaker channels most likely contribute to spikes that are not propagated on a depolarizing wave but on a flat hyperpolarized membrane potential (Marder and Selverston, 1992). The stippled box represents the muscle. The question mark signifies that Shaker and Shal are both present at the NMJ, but their locations in the component membranes are not known.

Similarly, it has been shown that oscillations are not present in the axon and that spikes are propagated on a flat, hyperpolarized membrane potential (Mulloney and Selverston, 1972; Marder et al., 1992) (for review, see Marder and Selverston, 1992). Thus, it is commonly thought that oscillations are generated in the neuropil. It may be that oscillations are generated in one or more localized compartments within the neuropil. Large neurites are good candidates for such compartments because they are strategically located between the spike initiation zone and the fine neuropil that receives an immense array of modulatory input that influences oscillatory and burst generating properties (Christie et al., 1997; Ayali and HarrisWarrick, 1999; Blitz and Nusbaum, 1999; Blitz et al., 1999; Fenelon et al., 1999; Kilman et al., 1999; Kloppenburg et al., 1999) (for review, see Harris-Warrick et al., 1997; Marder et al., 1997). Evidence for an oscillation generator in the large primary neurites of lobster cardiac neurons has already been reported (Tazaki and Cooke, 1983). We have shown that Shal, but not Shaker, channels are present in the somatodendritic compartment. Thus, Shal channels primarily mediate the $I_{\mathrm{A}}$ that influences oscillatory properties and that is regulated by neuromodulatory inputs.

Spikes are probably generated near the region in which the axon exits the STG, proximal to the dvn (Raper, 1979; Miller, 1980). The spike initiation zone (siz) is thought to have a high concentration of $\mathrm{Na}^{+}$channels, but its $\mathrm{K}^{+}$channel make-up is unknown. Neither Shaker nor Shal channels are detectably inserted into most neuronal processes as they leave the neuropil and enter the dvn. Instead, an A-channel-free zone exists (Fig. 9). Membrane-bound Shal channels are observed proximal to this zone, in the somatodendritic compartment, and membrane-bound Shaker channels are observed distally, in the axon. Interestingly, it has been shown that a molecular fence exists in the initial segment of hippocampal neurons, which physically limits the diff usion of membrane proteins to either side of the fence (Winckler and Mellman, 1999; Winckler et al., 1999). Thus, the boundary between the somatodendritic and 
axonal compartments lies in the initial segment, rather than in the axon hillock, which is located on average $33 \mu \mathrm{m}$ proximal to the fence. Based on the anatomy of hippocampal neurons, it is tempting to speculate that the beginning of the A-channel-free zone contains a domain analogous to the hippocampal initial segment molecular fence and that this marks the true boundary between the somatodendritic and axonal compartments. This analogy further predicts that the siz would be located just proximal to the A-channel-free zone, in the posterior region of the somatodendritic compartment. Unfortunately, the exact boundaries of the A-channel-free zone and the siz have not been clearly defined, and confirmation of this hypothesis will require more detailed ICC, including the possible localization of the siz by mapping the distribution of $\mathrm{Na}^{+}$channels. In any event, the data suggest that the main influence of the $I_{\mathrm{A}}$ on spike timing and frequency occurs primarily through Shal channels in the somatodendritic compartment.

It is generally thought that the function of the axon is to reliably transmit impulses generated at the siz to the muscle (Fig. 9). The strong anti-Shaker staining observed in the distal membranes of most axons suggests that Shaker channels contribute to spike propagation in pyloric neurons, as is true for Shaker channels in a variety of species (Wang et al., 1993; Rosenthal et al., 1996, 1997; Rogero et al., 1997). This observation is consistent with the fact that both sustained and transient $\mathrm{K}^{+}$currents exist in lobster axons (Connor, 1975). Interestingly, Shaker channel distribution is not uniform along an axon, and Shaker channels are missing from the proximal regions. We have shown that alternate splicing of shaker transcripts creates at least 16 Shaker channels that differ in their voltage dependence of activation and inactivation, as well as in their kinetics of inactivation (Kim et al., 1997, 1998). We do not know which of the 16 isoforms are localized to pyloric axons. However, because they all show rapid activation, any of the 16 shaker isoforms could be involved in immediately repolarizing a spike. We do not mean to imply that spike termination is the only role for Shaker channels in the axon. On the contrary, it is possible that both Shal and inactivating Shaker isoforms are localized to branch points in which they could contribute to phenomena such as branch point failure, as has been demonstrated for hippocampal A-channels (Debanne et al., 1997), or to specialized structures such as the secondary peripheral spike initiation zones (Meyrand et al., 1992).

Both Shaker and Shal channels are found at pyloric NMJs and thus participate in peripheral synaptic transmission. However, we cannot predict the specific function of each channel type because we do not know which channels are localized to the presynaptic and postsynaptic membranes. In Drosophila and mammals, both Shaker and Shal channels have been shown to be present in synaptic terminals in which they are thought to function in processes such as synaptic facilitation (Jan et al., 1977; Sheng et al., 1993; Wang et al., 1993, 1994; Martinez-Padron and Ferrus, 1997; Cooper et al., 1998). Additionally, Shaker channels are known to be postsynaptically clustered at larval NMJs in Drosophila (Tejedor et al., 1997; Zito et al., 1997), whereas Shal channels have been shown to be postsynaptically clustered in central mammalian neurons (Alonso and Widmer, 1997).

\section{Linearity between A-channel transcription, translation, and function}

Unlike other studies involving cultured neurons and developing cardiac myocytes (Xu et al., 1996; Wu et al., 1998), our measurements from acutely isolated adult pyloric neurons indicate that the amount of $\mathrm{K}^{+}$channel RNA correlates well with the amount of protein in five of six cell types and that the amount of protein correlates well with the size of the $I_{\mathrm{A}}$. The slopes of the best-fit lines differ considerably for the plots of $I_{\mathrm{A}}$ amplitude versus Shal channel density or transcript number (Fig. 4B) (Baro et al., 1997). As discussed in Materials and Methods, we believe this discrepancy stems from the fact that the protein measurements were not as sensitive and precise as the RNA measurements. However, in addition to the technical artifacts, the differences in the two lines could reflect real differences in Shal channel localization between cells. This is most obvious for the LP cell.

The number of Shal proteins in the LP cell is significantly less than we would predict based on the linear relationship between shal transcript number and $I_{\mathrm{A}}$ amplitude (Fig. 4). These data could reflect a differential localization of Shal channels in the LP cell relative to the other pyloric cell types. Using voltage clamp, we measured the $I_{\mathrm{A}}$ in the soma and proximal neurites; with single-cell RT-PCR, we measured the number of shal transcripts for the entire cell. However, when we estimated the relative amounts of Shal protein using staining intensity, we only considered Shal channels in the soma (see Materials and Methods). Therefore, one interpretation of these data is that Shal channels in the space-clamped compartment of the LP are mainly localized to the proximal neurites, whereas Shal channels in the space-clamped compartment of most other pyloric neurons are localized to both the soma and the proximal neurites. A second possible explanation could be that the predominant Shal isoform(s) in the LP soma is the alternate splice form(s) that is not recognized by the anti-Shal antibody. A third possibility is that shal gene expression in the LP cell is significantly downregulated at the translational or posttranslational levels relative to the other pyloric cell types. However, the fact that $I_{\mathrm{A}}$ conductance correlates with transcript number in the LP and all other pyloric neurons makes this third alternative less likely.

\section{Differential distribution of channels between cells}

The above discussion points out that, although Shaker and Shal channels consistently occupy defined compartments, the channels within a compartment may vary between cell types in two important respects that could influence the firing properties of the cell. First, the isoforms that are expressed may change. We would be unable to resolve this because our antibodies recognize most splice variants. Second, the distribution of isoforms within a compartment may vary. For example, it is possible that the somatodendritic compartment is made up of many subcompartments. Because alternate splicing generates at least 14 different Shal proteins that can interact to form heterotetramers (Baro, unpublished observations), $I_{\mathrm{A}}$ may be different in each subcompartment, and this could vary across cell types. In addition, differences in the expression and distribution of the 16 shaker isoforms could alter action potential propagation in the distal axons of different neurons.

\section{Conclusion}

Shaker and Shal channels are targeted to distinct compartments in pyloric neurons, and this imparts a different function to each channel type. Moreover, the unique placement, and consequently the function of each channel type, is conserved across cell types.

\section{REFERENCES}

Alonso G, Widmer H (1997) Clustering of KV4.2 potassium channels in postsynaptic membrane of rat supraoptic neurons: an ultrastructural study. Neuroscience 77:617-621.

Atwood HL, Govind CK, Jahromi SS (1977) Excitatory synapses of blue crab gastric mill muscles. Cell Tissue Res 177:145-158.

Atwood HL, Govind CK, Kwan I (1978) Nonhomogeneous excitatory synapses of a crab stomach muscle. J Neurobiol 9:17-28.

Ayali A, Harris-Warrick RM (1999) Monoamine control of the pacemaker kernel and cycle frequency in the lobster pyloric network. J Neurosci 19:6712-6722.

Baldwin DH, Graubard K (1995) Distribution of fine neurites of stomatogastric neurons of the crab Cancer borealis: evidence for a structured neuropil. J Comp Neurol 356:355-367.

Baro DJ, Harris-Warrick RM (1998) Differential expression and targeting of $\mathrm{K}^{+}$channel genes in the lobster pyloric central pattern generator. Ann NY Acad Sci 860:281-295.

Baro DJ, Coniglio LM, Cole CL, Rodriguez HE, Lubell JK, Kim MT, Harris-Warrick RM (1996a) Lobster shal: comparison with Drosophila shal and native potassium currents in identified neurons. J Neurosci 16:1689-1701.

Baro DJ, Cole CL, Harris-Warrick RM (1996b) RT-PCR analysis of shaker, shab, shaw, and shal gene expression in single neurons and glial cells. Receptors Channels 4:149-159.

Baro DJ, Levini RM, Kim MT, Willms AR, Lanning CC, Rodriguez HE, 
Harris-Warrick RM (1997) Quantitative single-cell-reverse transcriptionPCR demonstrates that A-current magnitude varies as a linear function of shal gene expression in identified stomatogastric neurons. J Neurosci 17:6597-6610.

Blitz DM, Nusbaum MP (1999) Distinct functions for cotransmitters mediating motor pattern selection. J Neurosci 19:6774-6783.

Blitz DM, Christie AE, Coleman MJ, Norris BJ, Marder E, Nusbaum MP (1999) Different proctolin neurons elicit distinct motor patterns from a multifunctional neuronal network. J Neurosci 19:5449-5463.

Christie AE, Baldwin DH, Marder E, Graubard K (1997) Organization of the stomatogastric neuropil of the crab, Cancer borealis, as revealed by modulator immunocytochemistry. Cell Tissue Res 288:135-148.

Connor JA (1975) Neural repetitive firing: a comparative study of membrane properties of crustacean walking leg axons. J Neurophysiol 351:922-932.

Cooper EC, Milroy A, Jan YN, Jan LY, Lowenstein DH (1998) Presynaptic localization of Kv1.4-containing A-type potassium channels near excitatory synapses in the hippocampus. J Neurosci 18:965-974.

Debanne D, Guerineau NC, Gahwiler BH, Thompson SM (1997) Actionpotential propagation gated by an axonal I(A)-like $\mathrm{K}^{+}$conductance in hippocampus. Nature [Erratum (1997) 390:536] 389:286-289.

Fenelon VS, Kilman V, Meyrand P, Marder E (1999) Sequential developmental acquisition of neuromodulatory inputs to a central patterngenerating network. J Comp Neurol 408:335-351.

Friend B (1976) Morphology and location of dense-core vesicles in the stomatogastric ganglion of the lobster, Panulirus interruptus. Cell Tissue Res 175:369-390.

Gola M, Selverston A (1981) Ionic requirements for bursting activity in lobster stomatogastric neurons. J Comp Physiol 145:191-207.

Golowasch J, Marder E (1992) Ionic currents of the lateral pyloric neuron of the stomatogastric ganglion of the crab. J Neurophysiol 67:318-331.

Govind CK (1979) Spatial distribution of excitatory innervation on a muscle fiber of the lobster (Homarus americanus). Cell Tissue Res 199:171-175.

Govind CK, Lingle CJ (1987) Neuromuscular organization and pharmacology. In: The crustacean stomatogastric system (Selverston AI, Moulins M, eds), pp 31-56. Berlin: Springer.

Graubard K, Hartline DK (1991) Voltage clamp analysis of intact stomatogastric neurons. Brain Res 557:241-254.

Graubard K, Ross WN (1985) Regional distribution of calcium influx into bursting neurons detected with arsenazo III. Proc Natl Acad Sci USA 82:5565-5569.

Harlow E, Lanr D (1988) Antibodies: a laboratory manual. Cold Spring Harbor, NY: Cold Spring Harbor Laboratory.

Harris-Warrick RM, Flamm RE (1987) Multiple mechanisms of bursting in a conditional bursting neuron. J Neurosci 7:2113-2128.

Harris-Warrick RM, Marder E, Selverston AI, Moulins M (1992) Dynamic biological networks: the stomatogastric nervous system, pp 209215. Cambridge, MA: MIT.

Harris-Warrick RM, Coniglio LM, Barazangi N, Guckenheimer J, Gueron S (1995a) Dopamine modulation of transient potassium current evokes phase shifts in a central pattern generator network. J Neurosci 15:342-358.

Harris-Warrick RM, Coniglio LM, Levini RM, Gueron S, Guckenheimer J (1995b) Dopamine modulation of two subthreshold currents produces phase shifts in activity of an identified motoneuron. J Neurophysiol 74:1404-1420.

Harris-Warrick R, Baro D, Coniglio L, Johnson B, Levini R, Peck J, Zhang B (1997) Chemical modulation of stomatogastric pattern generator networks. In: Neurons, networks, and motor behavior (Stein P, Grillner S, Selverston A, Stuart D, eds). Cambridge, MA: MIT.

Hartline D, Graubard K (1992) Cellular and synaptic properties in the crustacean stomatogastric nervous system. In: Dynamic biological networks (Harris-Warrick R, Marder E, Selverston A, Moulins M, eds), pp 31-85. Cambridge, MA: MIT.

Hartline DK (1979) Pattern generation in the lobster (Panulirus) stomatogastric ganglion. II. Pyloric network simulation. Biol Cybern 33:223-236.

Hartline DK, Gassie DV, Jones BR (1993) Effects of soma isolation on outward currents measured under voltage clamp in spiny lobster stomatogastric motor neurons. J Neurophysiol 69:2056-2071.

Hooper SL (1997a) Phase maintenance in the pyloric pattern of the lobster (Panulirus interruptus) stomatogastric ganglion. J Comput Neurosci 4:191-205.

Hooper SL (1997b) The pyloric pattern of the lobster (Panulirus interruptus) stomatogastric ganglion comprises two phase-maintaining subsets. J Comput Neurosci 4:207-219.

Hurley LM, Graubard K (1998) Pharmacologically and functionally distinct calcium currents of stomatogastric neurons. J Neurophysiol 79:2070-2081.

Jan YN, Jan LY, Dennis MJ (1977) Two mutations of synaptic transmission in Drosophila. Proc R Soc Lond B Biol Sci 198:87-108.

Kiehn O, Harris-Warrick RM (1992a) 5-HT modulation of hyperpolarization-activated inward current and calcium-dependent outward current in a crustacean motor neuron. J Neurophysiol 68:496-508.

Kiehn O, Harris-Warrick RM (1992b) Serotonergic stretch receptors in- duce plateau properties in a crustacean motor neuron by a dualconductance mechanism. J Neurophysiol 68:485-495.

Kilman V, Marder E (1996) Ultrastructure of the stomatogastric ganglion neuropil of the crab, Cancer borealis. J Comp Neurol 374:362-375.

Kilman V, Fenelon VS, Richards KS, Thirumalai V, Meyrand P, Marder E (1999) Sequential developmental acquisition of cotransmitters in identified sensory neurons of the stomatogastric nervous system of the lobsters, Homarus americanus and Homarus gammarus. J Comp Neurol 408:318-334.

Kim M, Baro DJ, Lanning CC, Doshi M, Farnham J, Moskowitz HS, Peck JH, Olivera BM, Harris-Warrick RM (1997) Alternative splicing in the pore-forming region of shaker potassium channels. $J$ Neurosci 17:8213-8224.

Kim M, Baro DJ, Lanning CC, Doshi M, Moskowitz HS, Farnham J, Harris-Warrick RM (1998) Expression of Panulirus shaker potassium channel splice variants. Receptors Channels 5:291-304.

King DG (1976a) Organization of crustacean neuropil. I. Patterns of synaptic connections in lobster stomatogastric ganglion. J Neurocytol 5:207-237.

King DG (1976b) Organization of crustacean neuropil. II. Distribution of synaptic contacts on identified motor neurons in lobster stomatogastric ganglion. J Neurocytol 5:239-266.

Kloppenburg P, Levini RM, Harris-Warrick RM (1999) Dopamine modulates two potassium currents and inhibits the intrinsic firing properties of an identified motor neuron in a central pattern generator network. J Neurophysiol 81:29-38.

Marder E (1974) Acetylcholine as an excitatory neuromuscular transmitter in the stomatogastric system of the lobster. Nature 251:730-731.

Marder E (1976) Cholinergic motor neurones in the stomatogastric system of the lobster. J Physiol (Lond) 257:63-86.

Marder E (1998) From biophysics to models of network function. Annu Rev Neurosci 21:25-45.

Marder E, Calabrese RL (1996) Principles of rhythmic motor pattern generation. Physiol Rev 76:687-717.

Marder E, Selverston A (1992) Modeling the stomatogastric nervous system. In: Dynamic biological networks (Harris-Warrick R, Marder E, Selverston A, Moulins M, eds), pp 31-85. Cambridge, MA: MIT.

Marder E, Weimann J, Kepler T, Abbott L (1992) Computational implications of a serotonin-sensitive region of axonal membrane on a dual function motor neuron. In: Analysis and modeling neurosystems II. (Eeckman F, ed). Boston: Kluwer.

Marder E, Jorge-Rivera J, Kilman V, Weiman J (1997) Peptidergic modulation of synaptic transmission in a rhythmic motor system. Adv Organismal Biol 2:213-233.

Martinez-Padron M, Ferrus A (1997) Presynaptic recordings from Drosophila: correlation of macroscopic and single-channel $\mathrm{K}^{+}$currents. J Neurosci 17:3412-3424.

Maynard EA (1971a) Electron microscopy of the stomatogastric ganglion in the lobster Homarus americanus. Tissue Cell 3:137-160.

Maynard EA (1971b) Microscopic localization of cholinesterases in the nervous systems of the lobsters Panulirus argus and Homarus americanus. Tissue Cell 3:215-250.

Meiss DE, Govind CK (1979) Multiterminal innervation: non-uniform density along single lobster muscle fibers. Brain Res 160:163-169.

Meyrand P, Weimann JM, Marder E (1992) Multiple axonal spike initiation zones in a motor neuron: serotonin activation. J Neurosci 12:2803-2812.

Miller JP (1980) Mechanisms underlying pattern generation in the lobster stomatogastric ganglion. In: Biology. San Diego: University of California, San Diego.

Miller JP (1987) Pyloric mechanisms. In: The crustacean stomatogastric system (Selverston AI, Moulins M, eds), pp 109-136. Berlin: Springer.

Morris LG, Hooper SL (1997) Muscle response to changing neuronal input in the lobster (Panulirus interruptus) stomatogastric system: spike number- versus spike frequency-dependent domains. J Neurosci 17:5956-5971.

Morris LG, Hooper SL (1998) Muscle response to changing neuronal input in the lobster (Panulirus interruptus) stomatogastric system: slow muscle properties can transform rhythmic input into tonic output. J Neurosci 18:3433-3442.

Mulloney B, Selverston A (1972) Antidromic region potentials fail to demonstrate known interactions between neurons. Science 177:69-72.

Patel V, Govind CK (1997a) Structural-functional differences of a crab motoneuron to four stomach muscles. J Neurocytol 26:389-398.

Patel V, Govind CK (1997b) Synaptic exocytosis of dense-core vesicles in blue crab (Callinectes sapidus) stomach muscles. Cell Tissue Res 289:517-526.

Premack BA, Thompson S, Coombs-Hahn J (1989) Clustered distribution and variability in kinetics of transient $\mathrm{K}$ channels in molluscan neuron cell bodies. J Neurosci 9:4089-4099.

Raper JA (1979) Nonimpulse-mediated synaptic transmission during the generation of a cyclic motor program. Science 205:304-306.

Rogero O, Hammerle B, Tejedor FJ (1997) Diverse expression and distribution of Shaker potassium channels during the development of the Drosophila nervous system. J Neurosci 17:5108-5118. 
Rosenthal JJ, Vickery RG, Gilly WF (1996) Molecular identification of SqKv1A. A candidate for the delayed rectifier $\mathrm{K}$ channel in squid giant axon. J Gen Physiol 108:207-219.

Rosenthal JJ, Liu TI, Gilly WF (1997) A family of delayed rectifier Kv1 cDNAs showing cell type-specific expression in the squid stellate ganglion/giant fiber lobe complex. J Neurosci 17:5070-5079.

Ross WN, Graubard K (1989) Spatially and temporally resolved calcium concentration changes in oscillating neurons of crab stomatogastric ganglion. Proc Natl Acad Sci USA 86:1679-1683.

Russell D, Hartline D (1984) Synaptic regulation of cellular properties and burst oscillations of neurons in gastric mill system of spiny lobsters, Panulirus interruptus. J Neurophysiol 52:54-73.

Salkoff L, Baker K, Butler A, Covarrubias M, Pak MD, Wei A (1992) An essential "set" of $\mathrm{K}^{+}$channels conserved in flies, mice and humans. Trends Neurosci 15:161-166.

Scholz NL, Chang ES, Graubard K, Truman JW (1998) The NO/cGMP pathway and the development of neural networks in postembryonic lobsters. J Neurobiol 34:208-226.

Sheng M, Liao YJ, Jan YN, Jan LY (1993) Presynaptic A-current based on heteromultimeric $\mathrm{K}^{+}$channels detected in vivo. Nature 365:72-75.

Stowell JN, Craig AM (1999) Axon/dendrite targeting of metabotropic glutamate receptors by their cytoplasmic carboxy-terminal domains. Neuron 22:525-536.

Tazaki K, Cooke I (1983) Separation of neuronal sites of driver potential and impulse generation by ligaturing in the cardiac ganglion of the lobster, Homarus americanus. J Comp Physiol 151:329-346.

Tejedor FJ, Bokhari A, Rogero O, Gorczyca M, Zhang J, Kim E, Sheng M, Budnik V (1997) Essential role for dlg in synaptic clustering of Shaker $\mathrm{K}^{+}$channels in vivo. J Neurosci 17:152-159.

Tierney AJ, Harris-Warrick RM (1992) Physiological role of the transient potassium current in the pyloric circuit of the lobster stomatogastric ganglion. J Neurophysiol 67:599-609.

Tkatch T, Baranauskas G, Surmeier DJ (2000) Kv4.2 mRNA abundance and A-type $\mathrm{K}^{+}$current amplitude are linearly related in basal ganglia and basal forebrain neurons J Neurosci 20:579-588.

Tsunoda S, Salkoff L (1995a) Genetic analysis of Drosophila neurons: Shal,
Shaw, and Shab encode most embryonic potassium currents. J Neurosci 15:1741-1754.

Tsunoda S, Salkoff L (1995b) The major delayed rectifier in both Drosophila neurons and muscle is encoded by Shab. J Neurosci 15:5209-5221.

Wang H, Kunkel DD, Martin TM, Schwartzkroin PA, Tempel BL (1993) Heteromultimeric $\mathrm{K}^{+}$channels in terminal and juxtaparanodal regions of neurons. Nature 365:75-79.

Wang H, Kunkel DD, Schwartzkroin PA, Tempel BL (1994) Localization of Kv1.1 and Kv1.2, two $\mathrm{K}$ channel proteins, to synaptic terminals, somata, and dendrites in the mouse brain. J Neurosci 14:4588-4599.

Willms AR, Baro DJ, Harris-Warrick RM, Guckenheimer J (1999) An improved parameter estimation method for Hodgkin-Huxley models. J Comput Neurosci 6:145-168.

Winckler B, Mellman I (1999) Neuronal polarity: controlling the sorting and diffusion of membrane components. Neuron 23:637-640.

Winckler B, Forscher P, Mellman I (1999) A diffusion barrier maintains distribution of membrane proteins in polarized neurons. Nature 397:698-701.

Wu RL, Butler DM, Barish ME (1998) Potassium current development and its linkage to membrane expansion during growth of cultured embryonic mouse hippocampal neurons: sensitivity to inhibitors of phosphatidylinositol 3-kinase and other protein kinases. J Neurosci 18:6261-6278.

Xu H, Dixon JE, Barry DM, Trimmer JS, Merlie JP, McKinnon D, Nerbonne JM (1996) Developmental analysis reveals mismatches in the expression of $\mathrm{K}^{+}$channel alpha subunits and voltage-gated $\mathrm{K}^{+}$channel currents in rat ventricular myocytes. J Gen Physiol 108:405-419.

Zhang B, Harris-Warrick RM (1995) Calcium-dependent plateau potentials in a crab stomatogastric ganglion motor neuron. I. Calcium current and its modulation by serotonin. J Neurophysiol 74:1929-1937.

Zhang B, Wootton JF, Harris-Warrick RM (1995) Calcium-dependent plateau potentials in a crab stomatogastric ganglion motor neuron. II. Calcium-activated slow inward current. J Neurophysiol 74:1938-1946.

Zito K, Fetter RD, Goodman CS, Isacoff EY (1997) Synaptic clustering of Fascilin II and Shaker: essential targeting sequences and role of Dlg. Neuron 19:1007-1016. 